\title{
Human Periprostatic Adipose Tissue: Secretome from Patients With Prostate Cancer or Benign Prostate Hyperplasia
}

\author{
PAULA ALEJANDRA SACCA ${ }^{1}$, OSVALDO NÉSTOR MAZZA ${ }^{2}$, CARLOS SCORTICATI ${ }^{2}$, \\ GONZALO VITAGLIANO $^{3}$, GABRIEL CASAS ${ }^{4}$ and JUAN CARLOS CALVO ${ }^{1,5}$ \\ ${ }^{1}$ Institute of Biology and Experimental Medicine (IBYME), CONICET, Buenos Aires, Argentina; \\ ${ }^{2}$ Department of Urology, School of Medicine, University of Buenos Aires, \\ Clínical Hospital "José de San Martín”, Buenos Aires, Argentina; \\ ${ }^{3}$ Department of Urology, Deutsches Hospital, Buenos Aires, Argentina; \\ ${ }^{4}$ Department of Pathology, Deutsches Hospital, Buenos Aires, Argentina; \\ ${ }^{5}$ Department of Biological Chemistry, School of Exact and Natural Sciences, \\ University of Buenos Aires, Buenos Aires, Argentina
}

\begin{abstract}
Background/Aim: Periprostatic adipose tissue (PPAT) directs tumour behaviour. Microenvironment secretome provides information related to its biology. This study was performed to identify secreted proteins by PPAT, from both prostate cancer and benign prostate hyperplasia (BPH) patients. Patients and Methods: Liquid chromatography-mass spectrometry-based proteomic analysis was performed in PPAT-conditioned media (CM) from patients with prostate cancer (CMs-T) (stage T3: CM-T3, stage T2: CM-T2) or benign disease (CM-BPH). Results: The highest number and diversity of proteins was identified in CM-T3. Locomotion was the biological process mainly associated to $C M s-T$ and reproduction to CM-T3. Immune responses were enriched in $C M s-T$. Extracellular matrix and structural proteins were associated to CMs-T. CM-T3 was enriched in proteins with catalytic activity and CM-T2 in proteins with defense/immunity activity. Metabolism and energy pathways were enriched in CM-T3 and those with immune system functions in CMs-T. Transport proteins were enriched in CM-T2 and CM-BPH. Conclusion: Proteins and pathways reported in this study could be useful to distinguish stages of disease and may become targets for novel therapies.
\end{abstract}

This article is freely accessible online.

Correspondence to: Paula Alejandra Sacca, Ph.D., Instituto de Biología y Medicina Experimental - CONICET, Laboratorio de Química de Proteoglicanos y Matriz Extracelular, Vuelta de Obligado 2490, CP 1428ADN, Ciudad Autónoma de Buenos Aires, Buenos Aires, Argentina. Tel: +54 1147832869 (ext 273), Fax: +54 1147862564, e-mail: psacca@ibyme.conicet.gov.ar

Key Words: Periprostatic adipose tissue, fat tissue, secretome, proteomic, prostate cancer, benign prostate hyperplasia, microenvironment.
Prostate cancer ( $\mathrm{PCa}$ ) is the second most common cancer in men worldwide. While most men have indolent disease, which can be treated properly, the problem consists in reliably distinguishing between indolent and aggressive disease. Evidence shows that the microenvironment affects tumour behavior.

Adipose tissue microenvironment is now known to direct tumour growth, invasion and metastases $(1,2)$. Adipose tissue is adjacent to the prostate gland and the site of invasion of PCa. Periprostatic adipose tissue (PPAT) was present on $48 \%$ of prostatic surfaces. The distribution of periprostatic adipose tissue varied among the different surfaces of the prostate, with the anterior, posterior, right, and left surfaces showing 44\%, 36\%, 59\%, and 57\% adipose tissue, respectively (3). Recent evidence demonstrates that adipose tissue is not only an energy storage reservoir, but also a metabolically active organ (4) that produces hormones, growth factors, adipokines (5) and other molecules that not only affect physiological cellular responses, but also contribute to paracrine and autocrine signalling networks, especially in tumour microenvironments where hormonal dependence mediates cancer progression (611). Adipose tissue contains adipose-derived stem cells (mesenchymal stem cells), preadipocytes and adipocytes in different degrees of differentiation, endothelial cells, macrophages, fibroblasts, blood vessels and inflammatory cells that can modulate the tissue secretion pattern via interaction with different cell types and nearby organs. There is a two-way paracrine regulation between $\mathrm{PCa}$ cells and cells that make up adipose tissue. Adipose microenvironment is involved in signalling pathways that influence $\mathrm{PCa}$ progression. Finley et al. (6) showed that PPAT is a modulator of PCa aggressiveness through the secretion of high local levels of IL-6. They found that IL-6 levels in 
PPAT but not in the serum were correlated with higher Gleason score, interestingly highlighting that the concentration of factors found in the local microenvironment of a tumour may not reflect the levels detected in peripheral blood. IL-6 can activate the androgen receptor and may promote intracellular synthesis of androgens in the prostate (12). Cytokines synthesized by fat-resident regulatory and conventional $\mathrm{T}$ cells could directly affect the synthesis of inflammatory mediators. In vitro data suggest that adipose stem cells can increase the production of cytokines and growth factors, thus resulting in PCa invasive growth and metastasis (13). More recent studies have shown that PPAT secretes factors that alter the microenvironment of the $\mathrm{PCa}$, promoting proliferation, survival or motility. Results from our laboratory (10) showed that factors secreted by PPAT may be influencing tumour behavior. We verified a weak attachment of LNCaP cells (relative to control medium) to components of PPAT from patients with PCa. Contrarily, PC3 cells showed increased attachment to components of PPAT from patients with PCa or benign disease. Moreover, we found that PPAT from men with PCa produced and released higher proMMP-9 than men with benign prostatic hyperplasia (BPH). Also, Ribeiro et al. (13) observed that PPAT secreted metalloproteases in PCa patients. In addition, they found altered genes related to the cellular activity of adipose tissue in overweight/obese subjects and a downward impact on immunity and inflammation, mainly related to the complement system (down-regulation of $\mathrm{CFH}$ ).

It is now known that interaction between PCa cells and PPAT microenvironment is a process driving cancer aggressiveness (14-16). Secreted proteins into the microenvironment play a role in the regulation of both, physiological and pathophysiological processes. Such secreted proteins include growth factors, ECM degrading enzymes, cell motility factors, angiogenic factors and immunoregulatory cytokines participating in various physiological processes such as immune defense and cell signalling. Bioactive molecules also play critical roles in processes that include cancer promotion, cell differentiation, invasion, metastasis and angiogenesis by regulating cell-cell adhesion and ECM interactions. However, there is not enough knowledge about which proteins are secreted by PPAT both in healthy or diseased conditions. Hence, a detailed characterization of secreted proteins which take part in the bi-directional heterotypic cross-talk and their critical role in cell physiology and signalling pathways may increase understanding of the disease and facilitate development of improved therapies. Another point to be considered is the fact that regional differences in the production of proteins from fatty deposits have been documented. Regarding the study of PPAT coming from patients with BPH (B-PPAT), it is interesting not only to compare it with PPAT coming from patients with tumours (TPPAT), but also to determine the secretome from such a benign pathology, due to the impossibility of obtaining PPAT samples from healthy subjects.

Several studies performed secretome analysis of separate adipose tissue-derived cell types but, they did not reflect the secretome of adipose tissue as a whole, considering the crosstalk between different cell types from within the same adipose tissue (17). Furthermore, it is now known that adipose tissue composition and secretome differ depending on the location in the body and on the disease stage, as in cancer (17).

Herein, we propose to identify secreted proteins by PPAT from, both $\mathrm{PCa}$ (T3 and $\mathrm{T} 2$ stage) and benign prostate hyperplasia (BPH) patients, using liquid chromatography and mass spectrometry analysis with the Orbitrap technology. For this purpose, conditioned medium was collected from PPAT explants of human samples and, then a bioinformatics analysis was carried out.

\section{Patients and Methods}

Ethics statement and tissue procurement. Human PPAT was obtained from 15 patients. Ten patients were undergoing radical prostatectomy for prostate tumours. Of these, five were at T3 stage (PPAT-T3, age range $=57-70$ years, BMI range $37.0-26.1 \mathrm{~kg} / \mathrm{m}^{2}$ ) and five were at $\mathrm{T} 2$ stage (PPAT-T2, age range $=57-66$ years). Five patients were undergoing adenomectomy for BPH (PPAT-B, age range $=68-71$ years, BMI range $=21.9-30.2 \mathrm{~kg} / \mathrm{m}^{2}$ ). None of the patients received preoperative therapy. All patients gave their written consent for this research and the corresponding ethics committee from both the hospital and IBYME approved the procedures. In every case, once the anterior surface of the prostate had been surgically exposed, the fat tissue surrounding the superficial venous plexus of Santorini was dissected. A fatty, loose tissue surrounds this plexus on both sides of the inferior portion of the anterior surface of the prostate and, approximately, 0.5-2 $\mathrm{g}$ of this fat tissue was separated for further processing. Clinical and pathological characteristics of the specimens used (pTNM, Gleason score, age and BMI) are shown in Table I. All BPH specimens showed histological epithelial and/or stromal cell hyperplasia but no malignant cells.

Conditioned media from PPAT. PPAT explants were processed under sterile conditions within $2 \mathrm{~h}$ after surgery. Tissue was transferred to a centrifuge tube and carefully washed three times with $45 \mathrm{ml}$ icecold phosphate buffer saline solution (PBS) and supplemented with gentamicin (GIBCO, NY, USA) $(50 \mu \mathrm{g} / \mathrm{ml})$. Washed tissue was transferred to a centrifuge tube containing $35 \mathrm{ml} \mathrm{PBS}$ at $37^{\circ} \mathrm{C}$ and centrifuged at $277 \times g$ at RT to remove red blood cells. Whole tissue was then weighed. Tissue was then placed in a culture flask with M199 culture medium (Sigma, St. Louis, MO, USA) (normalizing $1 \mathrm{~g}$ tissue/10 ml M199), supplemented with gentamicin $(50 \mu \mathrm{g} / \mathrm{ml})$ and incubated at $37^{\circ} \mathrm{C}$ in $5 \% \mathrm{CO}_{2}$. After $1 \mathrm{~h}$, medium was replaced with fresh medium and incubated for another $24 \mathrm{~h}$. The resulting conditioned medium (PPAT-CM) was collected, centrifuged, filtered and stored at $-80^{\circ} \mathrm{C}$ until use (18). M199 incubated in the same conditions was used as control medium. After its collection, in addition to secreted proteins, conditioned medium may also contain shed membrane proteins and secretory vesicles (e.g. microvesicles, exosomes, and membrane particles). Both, centrifugation of the medium after collection and filtration (used for removal of non- 
Table I. Clinical and pathological characteristics of patients.

\begin{tabular}{lccccccc}
\hline Pathology & Pathologic stage & $\mathrm{n}$ & Gleason score & Age (years) & $p$-Value & BMI $\left(\mathrm{kg} / \mathrm{m}^{2}\right)$ & $p$-Value \\
\hline BPH & & 5 & & $68.4 \pm 1.7$ & & $25.3 \pm 3.5$ \\
PCa & pT2b-c & 5 & $\leq 7$ & $65.4 \pm 4.3$ & & $26.7 \pm 3.2$ & 0.166 \\
& pT3a & 5 & $\leq 7$ & $62.6 \pm 5.1$ & $29.4 \pm 5.0$ & 0.372 \\
\hline
\end{tabular}

Data was presented like a media \pm standard deviation: differences between groups were calculated using the $t$-test. BPH: Benign prostate hyperplasia; PCa: prostate cancer.

adherent cells and debris) will leave the secretory vesicles in the medium (together with Golgi membranes). Thus, secretory vesicle proteins can be released into the conditioned medium during processing and they can constitute a fraction of the secretome (19).

Collection of conditioned media for analysis. For secretome analysis equal volume of PPAT-CM was collected from each patient and separated into three groups: a) patients with PCa stage T3 (CM-T3; $\mathrm{n}=5)$; $b$ ) patients with PCa stage T2 (CM-T2; $=5)$ and c) group of $\mathrm{CMs}$ derived from patients with $\mathrm{BPH}(\mathrm{CM}-\mathrm{BPH} ; \mathrm{n}=5)$. The amount of proteins in the CMs was quantified using Nanodrop 2000 (Thermo Scientific, Waltham, MA, USA). Control medium was used as blank.

Liquid chromatography and mass spectrometry analysis. Protein digestion and Mass Spectrometry analysis were performed at the Proteomics Core Facility CEQUIBIEM, at the University of Buenos Aires/CONICET (National Research Council) as follows: protein samples were treated with dithiotreitol (DTT) in $50 \mathrm{mM}$ ammonium bicarbonate at a final concentration of $10 \mathrm{mM}\left(45 \mathrm{~min}, 56^{\circ} \mathrm{C}\right)$ and alkylated with iodoacetamide in the same solvent at a final concentration of $20 \mathrm{mM}$ (40 min, RT, in darkness). This protein solution was precipitated with $1 / 5$ volume of trichloroacetic acid (TCA) at $-20^{\circ} \mathrm{C}$ for at least $2 \mathrm{~h}$ and, then, centrifuged at maximum speed for $10 \mathrm{~min}\left(4^{\circ} \mathrm{C}\right)$. The pellet was washed twice with ice-cooled acetone and dried at RT. Proteins were resuspended in $50 \mathrm{mM}$ ammonium bicarbonate, $\mathrm{pH}=8$ and digested with trypsin (Promega V5111, Madison, WI, USA). Then, the peptides were purified and desalted with ZipTip C18 columns (Millipore, MA, USA). The digests were analyzed by nanoLC-MS/MS in a Thermo Scientific QExactive Mass Spectrometer coupled to a nanoHPLC EASY-nLC 1000 (Thermo Scientific). For the LC-MS/MS analysis, approximately $1 \mu \mathrm{g}$ of peptides was loaded onto the column and eluted for $120 \mathrm{~min}$ using a reverse phase column $(\mathrm{C} 18,2 \mu \mathrm{m}, 100 \mathrm{~A}$, $50 \mu \mathrm{m} \times 150 \mathrm{~mm}$ ) Easy-Spray Column PepMap RSLC (P/N ES801) suitable for separating protein complexes with a high degree of resolution. Solvent A was $0.1 \%$ formic acid in water whereas B was $0.1 \%$ formic acid in acetonitrile. The flow rate used for the nano column was $300 \mathrm{nl} \mathrm{min-1}$ and the solvent ranged from 7\% B (5 min) to $35 \%$ (120 min). The injection volume was $2 \mu \mathrm{l}$. The MS equipment has a high collision dissociation cell (HCD) for fragmentation and an Orbitrap analyzer (Thermo Scientific, Q-Exactive). A voltage of 3.5 $\mathrm{kV}$ was used for Electro Spray Ionization (Thermo Scientific, EASYSPRAY). XCalibur 3.0.63 (Thermo Scientific) software was used for data acquisition and the equipment configuration allowed peptide identification along with chromatographic separation. Full-scan mass spectra were acquired in the Orbitrap analyzer. The scanned mass range was $400-1800 \mathrm{~m} / \mathrm{z}$, at a resolution of 70,000 at $400 \mathrm{~m} / \mathrm{z}$ and the twelve most intense ions in each cycle, were sequentially isolated, fragmented by HCD and measured in the Orbitrap analyzer. Peptides with a charge of +1 or with unassigned charge state were excluded from fragmentation for MS2.

Analysis of MS data. Q Exactive raw data were processed using Proteome Discoverer software (version 2.1.1.21 Thermo Scientific) and searched against Homo sapiens protein sequences database with trypsin specificity and a maximum of one missed cleavage per peptide. Carbamidomethylation of cysteine residues was set as a fixed modification and oxidation of methionine was set as a variable modification. Proteome Discoverer searches were performed with a precursor mass tolerance of $10 \mathrm{ppm}$ and product ion tolerance of $0.05 \mathrm{Da}$. Static modifications were set to carbamidomethylation of Cys, and dynamic modifications were set to oxidation of Met and $\mathrm{N}$-terminal acetylation. Protein hits were filtered for high confidence peptide matches with a maximum protein and peptide false discovery rate of $1 \%$ calculated by employing a reverse database strategy.

Protein categorization. To understand the role of identified proteins in cell biology, they were integrated and interpreted through several bioinformatics tools. Proteins detected in secretome of PPAT-CMs were classified based on the PANTHER system (Protein ANalysis THrough Evolutionary Relationships) (www.pantherdb.org/) (Version 13.1, released 2018-02-03). It is a resource that classifies genes and proteins based on their reported biological processes, molecular functions, cellular components, protein classes and pathways. Furthermore, FunRich was used (http://www.funrich.org/) (Functional Enrichment analysis tool) mainly for enrichment test which has been performed against Homo Sapiens background (20). Also, CM proteins were subjected to in silico analysis using ProteINSIDE tool (http://www.proteinside.org) (21) (workflow version 1.2/last update 13-Mar-2017) to predict classic secretion of proteins (endoplasmic reticulum/Golgi apparatus dependent pathway) through the SignalP tool (version 4.1]) and to identify proteins that are putatively secreted by non-classical protein exports or ER/Golgi-independent protein secretions. ProteINSIDE checks the sub-cellular localazation of proteins and compares their annotation relatively to the list of GO terms related to secretion. Lastly, to support these predictions (classical and non-classical ways) ProteINSIDE runs the TargetP software (22) that predicts the subcellular localazation of proteins using the amino acid sequence. The double query of protein secretion both by the peptide signal prediction from protein sequence and the GO annotation is unique to ProteINSIDE (21). SignalP (discrimination score) discriminates signal peptides from non-signal peptides ( 0 to 1 where 1 is the best) and TargetP score (reliability class) from 1 to 5 , where 1 indicates the strongest prediction. 
A

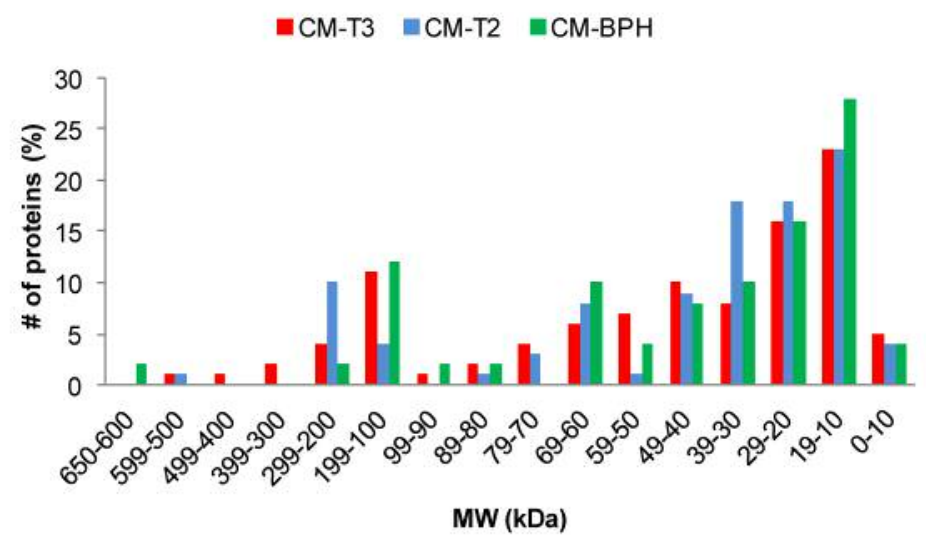

B

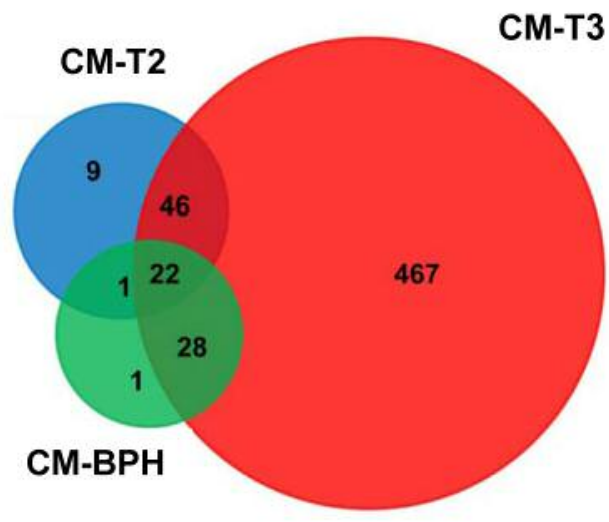

Figure 1. Distribution of proteins detected in conditioned media of periprostatic adipose tissue according to their molecular weights (MW) as obtained from MS analysis (A). Venn diagram depicting the number of specific and common proteins (B).

Overrepresentation test has been performed against Homo sapiens background using functional annotation data set provided in Panther. The exponentially modified protein abundance index (emPAI) (23) was used for protein abundance comparison.

Statistical methods. Statistical analysis was performed using GraphPad Prism software (La Jolla, CA, USA). T-test was used for testing clinico-pathological data and ANNOVA with Dunn's post test for protein quantification. Benjamini and Hochberg (BH) false discovery rate method was taken into consideration in enrichment data analysis for $p$ - corrected value. $p$-Values less than 0.05 were considered statistically significant.

\section{Results}

No significant differences were found in age or body mass index (BMI) between PCa and BPH patients. However, patients with advanced cancer had a higher average body mass index compared to patients with benign pathology. The amount of proteins was $22.5 \pm 1.7 \mu \mathrm{g} / \mathrm{ml}, 34.5 \pm 6.4 \mu \mathrm{g} / \mathrm{ml}$ and $7.3 \pm 1.3 \mu \mathrm{g} / \mathrm{ml}$ in CM-T3, CM-T2 and CM-BPH, respectively PPAT-CM derived from patients with tumour (CMs-T) contained higher amount of proteins relative to CM-BPH. There were no significant differences in the amount of proteins between CMs-T, but there was a significant difference in the amount of proteins between CM-T2 and CM-BPH $(p<0.05)$. A total of 574 PPAT proteins were identified by MS approach. The molecular weight (MW) of the proteins detected in this study ranged from $628.7 \mathrm{kDa}$ (neuroblast differentiation-associated protein AHNAK) to 3.6 kDa (proteasome subunit alpha type-2 (PSMA2, fragment). The number of proteins distributed between the three groups of CMs, according to their MWs, is shown in Figure 1A.
Most of the detected proteins have a MW between 10 and 30 $\mathrm{kDa}$ and nearly $50 \%$ of them were below $40 \mathrm{kDa}$, while $80 \%$ of the total proteins had a MW below $70 \mathrm{kDa}$. Proteins in the range of 100 to $199 \mathrm{kDa}$ were also detected in CM-T3 and CM-BPH, while proteins from CM-T2 had MW in the range of 200 to $299 \mathrm{kDa}$. Using this proteomic approach, it was possible to detect several proteins below $10 \mathrm{kDa}$ and above $200 \mathrm{kDa}$, a range that is outside the separation limits of conventional two-dimensional gel electrophoresis.

To know which proteins are specific or overlap within the three groups of CMs, the protein accession numbers from each $\mathrm{CM}$ were introduced in a three-way Venn diagram tool (Figure 1B). The highest number of identified proteins corresponded to CMs-T. Patients in T3 stage had the highest number of identified proteins (563), followed by CM-T2 (78 proteins) and patients with benign disease (52 proteins). The number of specific proteins in the three groups was 477 of which 467 $(81.4 \%)$ were specific for CM-T3. Probably, this group of proteins might contain bioactive molecules contributing to progression of PCa. Nine proteins $(1.6 \%)$ were specific for $\mathrm{CM}-\mathrm{T} 2$ and only one protein $(0.2 \%)$ was specific for CM$\mathrm{BPH}$. The CMs-T shared 46 proteins $(8 \%)$, while 28 proteins (4.9\%) were common in CM-T3 and CM-BPH, and one protein $(0.2 \%)$ was common in CM-T2 and CM-BPH. The three groups of CMs shared 22 proteins (3.8\%). Table II shows a list of the identified genes that arised from this analysis. Two uncharacterized proteins were detected in CMT3 with MW of 8.3 and $40.4 \mathrm{kDa}$, respectively.

Proteins expressed by adipose tissue were detected in the three CMs. Among them, adipocyte fatty acid-binding protein (FABP4, involved in lipid transport), isoform 2 of 
Table II. Gene name (GN) of specific or shared proteins identified by MS in the conditioned media from periprostatic adipose tissue.

\begin{tabular}{|c|c|}
\hline $\mathrm{CM}$ & Gene name \\
\hline $\mathrm{BPH}, \mathrm{T} 2$ and $\mathrm{T} 3$ & $\begin{array}{l}\text { A2M ADH1B APOA1 COL14A1 COL6A3 DDAH2 FABP4 FLNA GPI HBA1 HIST1H4A HP IGKV1D-33 } \\
\text { LGALS1 LMNA MYH7 PLIN4 SERPINA1 TF THBS1 THBS1 TPM4 VIM }\end{array}$ \\
\hline $\mathrm{BPH}$ and $\mathrm{T} 2$ & APOA2 \\
\hline $\mathrm{BPH}$ and $\mathrm{T} 3$ & $\begin{array}{l}\text { A1BG ACTN1 ACTN4 AHNAK ANXA2 APOA4 COL15A1 CYB5A CYB5A FGA FGB FN1 HPX HSPE1 } \\
\text { IGHG3 IGKC IGLC2 JUP PGM1 PRDX1 RNH1 RSU1 S100A9 } \\
\text { SERPINE1 TAGLN2 TKT TPM1 TPM3 TUBA1A }\end{array}$ \\
\hline $\mathrm{T} 2$ and $\mathrm{T} 3$ & $\begin{array}{l}\text { ACTB AKR1C3 ALDH1A1 ALDH2 ANK1 ANXA1 APOH BCAM BCAP31 C4A CD248 DES EHD2 EPB41L3 } \\
\text { FGG HBD HIST1H2BK HRNR IGHA1 IGHA2 IGHM IGLV3-21 IGKV3-20 IGHM KNG1 LAMB2 LRG1 } \\
\text { MSN OLFML1 ORM1 ORM2 PLEC PSMA1 PSMB4 PTX3 SERPINC1 SOD3 SORBS1 SPTA1 SPTAN1 } \\
\text { SPTBN1 TLN1 TNXB TPI1 VCL YWHAG }\end{array}$ \\
\hline $\mathrm{BPH}$ & HNRNPD \\
\hline $\mathrm{T} 2$ & AHSG ANXA6 F12 HNRNPA2B1 IGHV4-34 IGHV3-33 LPP NSFL1C SORBS2 \\
\hline $\mathrm{T} 3$ & 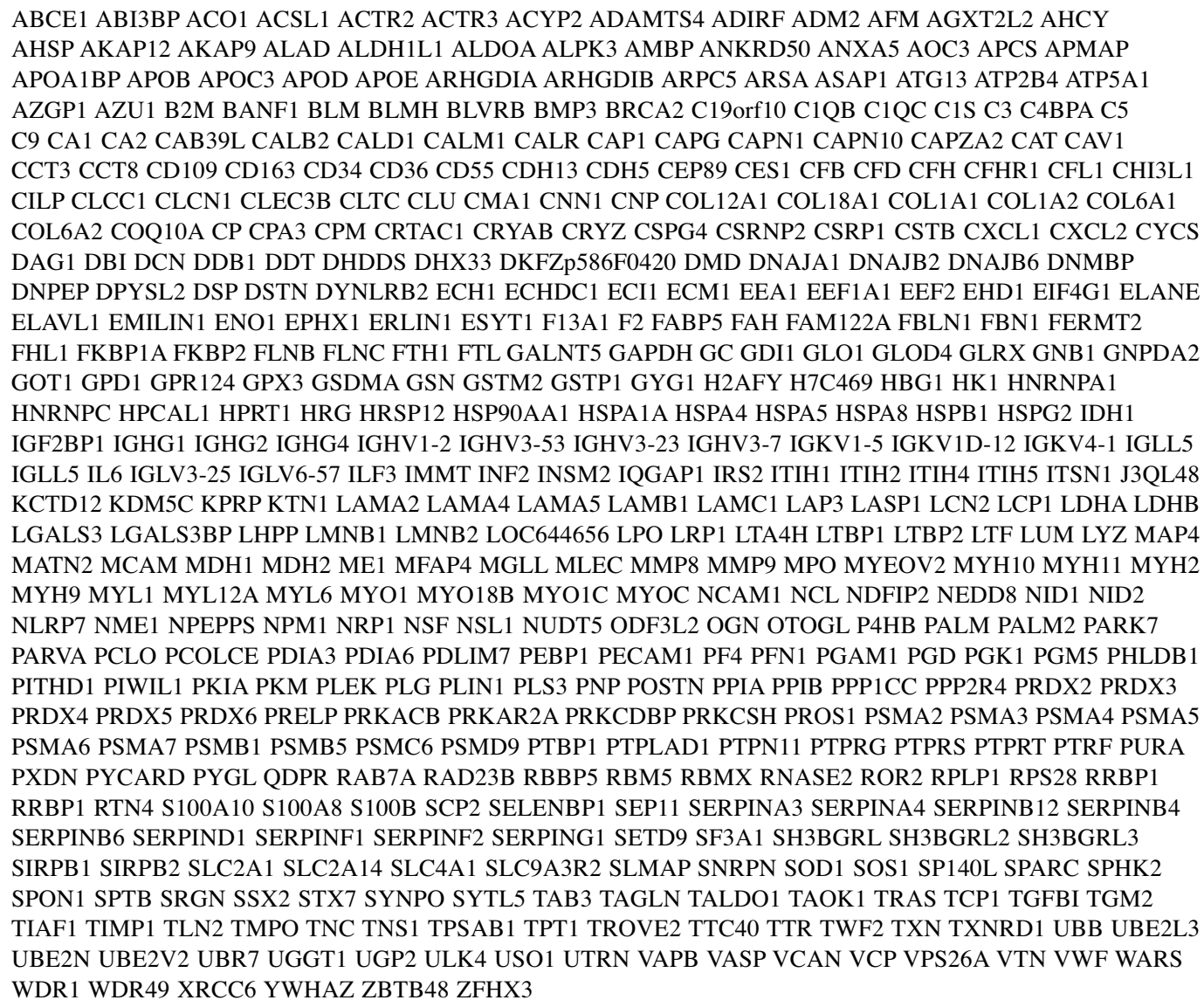 \\
\hline
\end{tabular}

perilipin-4 (PLIN4, whose major role is in lipid droplet formation) and haptoglobin (HP), were released by explants of human visceral and subcutaneous adipose tissue (24). Also, as expected, proteins secreted during human adipogenesis were detected in the three CMs. Some of them were: isoform 2 of Collagen alpha-3(VI) chain (COL6A3) and alcohol dehydrogenase $1 \mathrm{~B}(\mathrm{ADH} 1 \mathrm{~B}$, plays a major role in ethanol catabolism), filamin-A (FLNA), glucose-6- phosphate isomerase (GPI), galectin-1 (LGALS1), prelaminA/C (LMNA), serotransferrin (TF), thrombospondin-1 (THF), isoform 2 of Tropomyosin alpha-4 (TPM4), alpha2-macroglobulin (A2M) and vimentin (VIM) (25).

The unique protein detected in CM-BPH that was not shared between CMs-T was heterogeneous nuclear ribonucleoprotein D0 (HNRNPD/AUF1, a transcriptional regulator). Recent findings show that hnRNP proteins are 
crucial factors implicated in maintenance of stem cell selfrenewal, pluripotency and cell differentiation (26). Previous studies on secretory proteomes detected this protein in human adipose stromal vascular fraction (coming from subcutaneous adipose tissue obtained during elective surgery) (27) and also during adipogenesis of preadipocytes coming from subcutaneous fat tissue (females undergoing panniculectomy surgery) (25).

Proteins exclusively detected in CM-T2 were: alpha-2-HSglycoprotein/fetuin-A (AHSG), annexin (ANXA6), coagulation factor XII (F12), isoform A2 of heterogeneous nuclear ribonucleoproteins A2/B1 (HNRNPA2B1), lipoma-preferred partner (LPP), isoform 4 of NSFL1 cofactor p47 (NSFL1C), isoform 9 of Sorbin and SH3 domain-containing protein 2 (SORBS2), Ig heavy chain V-I region V35 (IGHV4-34) and Ig heavy chain V-III region KOL (IGHV3-33). Recent works identified the presence of AHSG in the secretome of rat white adipose tissue. Visceral adipose tissue expresses and secretes AHSG, however, its secretion pattern and function are poorly understood (28). In an animal model of obesity, AHSG induced inflammation in adipocytes by deregulating energy sensors (29). AHSG has been implicated in diverse normal and pathological processes including vascular calcification and bone metabolism regulation, insulin resistance, protease activity control, keratinocyte migration and breast tumour cell proliferative signalling (30). It is a major serum cell attachment factor particularly for tumour cells (31). In the presence of fetuin-A, detached tumour cells (like breast and colorectal) secreted exosomes which contained, in addition to other exosomal proteins, fetuin-A and histones. These exosomes mediated adhesion and cell spreading (32). Annexin-2 (ANXA2) (not detected in CM-T2) and annexin-6 (ANXA6) were required in fetuin-A mediated cell adhesion (32). AHSG/fetuin-A is an established tumour antigen in several types of cancer, including breast, glioblastoma, and pancreas cancer and was detected in serum samples from patients with a diagnosis of early-stage breast cancer (33). Serum autoantibodies reactive to fetuin, showed utility as a prognostic indicator for $\mathrm{PCa}$ patients at risk of progressing to metastatic disease (34). In adipocytes, annexin (ANXA6) protein expression was up-regulated by high fat diet as well as oxidative stress (35). With respect to their relationship with cancer, low levels of ANXA6 expression were detected in localized $\mathrm{PCa}$ and were reduced during progression of the disease (36). ANXA6, identified in exosomes derived from human mesothelioma cells $(37,38)$, regulates membranecytoskeleton dynamics and membrane-fusion events between intracellular compartments and plays a role in the inward vesiculation process (39). Another detected protein was isoform A2 of heterogeneous nuclear ribonucleoproteins A2/B1 (HNRNPA2B1) which is an RNA-binding protein reported to be up-regulated in cancer. Its overexpression mediates unregulated proliferation of PCa cells and a trend towards overexpression was also reported for nuclear hnRNPA2 protein in PCa as compared with BPH. Cytoplasmic hNRNPA2 was found in aggressive cancer. Although its function has not been characterized, this protein may affect the cancer cell phenotype through 3'-UTR mRNA-mediated regulation of $\beta$-catenin expression and other cancer-relevant genes (40). Exosomes contain specific repertoires of mRNAs, microRNAs (miRNAs) and other non-coding RNAs that can be functionally transferred to recipient cells. HNRNPA2/B1 is a key player in the sorting of miRNA in exosomes and provides potential tools for the packaging of selected regulatory RNAs in exosomes, which are of interest in biomedical applications (41). No reports were found about this protein in relation to adipose tissue. Lipoma-preferred partner (LPP) is a member of the zyxin family of LIM proteins that has been characterized as a promoter of mesenchymal/fibroblast cell migration. More recently, it has emerged as a critical inducer of tumour cell migration, invasion and metastasis. LPP contributes to malignant phenotype by its ability to shuttle into the nucleus, localize to adhesions and, most recently, to promote invadopodia formation (42). However, it has been determined that in breast cancer, invadopodia formation, cell extravasation and metastasis require an intact LPP LIM domain and the ability of LPP to interact with $\alpha$-actinin (43). Another protein detected in CM-T2 was isoform 9 of Sorbin and SH3 domaincontaining protein 2 (SORBS2). It is an adipose tissue depotspecific gene; more methylated and less expressed in subcutaneous adipose tissue than in omental visceral adipose tissue (OVAT) in both non-obese and obese subjects and a strong association of SORBS2 methylation with BMI was found in OVAT (44).

Only one overlapping protein was found between CM-T2 and CM-BPH: apolipoprotein A-II (APOA2). It is a cargo protein, predicted secreted, associated with lipoprotein metabolism and general inflammation. It was recently detected in the secretome of breast cancer-associated adipose tissue (17). Interestingly, ApoA-II was reported overexpressed in serum of individuals with $\mathrm{PCa}$ who have normal prostate-specific antigen (0-4.0 ng/ml), suggesting a potential utility as a marker in identifying indolent disease (45). Likewise, APOA2 appeared to be down-regulated in patients with PCa (stage I or II) when compared to those with $\mathrm{BPH}$ in $2 \mathrm{DE}$ protein profiles of serum samples (46). All these data suggest that APOA2 deserves an in-depth study to determine the usefulness of this protein in distinguishing prostatic pathologies.

Among the 46 proteins detected in both CMT-3 and CM-T2 were proteins of the spectrin family (SPTA1, SPTAN1, SPTBN1). Spectrins contribute to cell adhesion and migration, interact with structural and regulatory proteins and are involved in the regulation of DNA repair. Deregulation of spectrins, particularly SPTAN1, seriously affects cellular behavior and promotes tumour progression (47). Spectrin alpha chain, nonerythrocytic 1 (SPTAN1), spectrin beta chain, non-erythrocytic 
1 (SPTBN1) and two alpha-1-acid glycoprotein (ORM1 and ORM2, acute phase proteins) were also detected in breast cancer-associated adipose secretome (17). Another protein detected in CMs-T was galectin-3 (LGALS3). It has been reported that galectin-3, a proteolytic substrate for prostatespecific antigen, binds to several ligands in human prostasomes, such as ORM1 (48). Also, proteins involved in focal adhesion like actin cytoplasmic 1 (ACTB), moesin (MSN), annexin A1 (ANXA1), isoform 1 of vinculin (VCL), talin-1 (TLN1), cell movement (VCL, TLN1, MSN, ACTB) and invadopodium (MSN), were detected. Extracellular superoxide dismutase $[\mathrm{Cu}-$ $\mathrm{Zn}$ ] (SOD3) that protects the extracellular matrix from degradation by reactive oxygen species was also found in CMsT. Proteins involved in immune response were also detected in the CMs-T (IGLV3-21, IGKV3-20, IGHA1, IGHA2).

Table III shows a list of the top ten proteins detected in each CM. The top ten proteins exclusively detected in CMT3, were isoform 4 of myosin-11 (MYH11) and myosin-9 (MYH-9). SPATN1 was detected as one of the top ten proteins in both CM-T2 and CM-T3. The top ten proteins found in the list of CM-T2 (but also detected in CM-T3), were laminin subunit beta-2 (LAMB2), talin-1 (TLN1), hornerin (HNRN) and hemoglobin subunit delta (HBD). The top ten proteins of CM-BPH were shared by CM-T3 and/or CMT2. CM-T3 proteins were involved in angiogenesis, cell adhesion and cell shape (FN1, MHY9), cellular reshaping, movement and transport (MHY11). Cell-cell and cell-matrix adhesion (LAMB2), cellular and protein metabolic processes (HRNR), cellular morphogenesis (TLN1) and transport (TF and HBD) proteins were associated to CM-T2. CM-T3 and CM-T2 sharied proteins associated with cellular processes (FLNA, SPTAN1) and cellular morphogenesis like vimentin (VIM). Metabolic processes (alcohol dehydrogenase 1B (ADH1B); transketolase, (TKT); apolipoprotein A-I (APOA1) and isoform 2 of tropomyosin alpha-4 chain (TPM4)), cell adhesion (isoform 2 of collagen alpha-3(VI) chain (COL6A3)) and cellular morphogenesis (tropomyosin 1 alpha (TPM1)) proteins were associated with CM-BPH.

Functional protein classification. A UniProt search was performed to obtain information about the two uncharacterized proteins detected in CM-T3. One of them has aspartic-type endopeptidase activity and in the biological process category corresponds to autophagy, protein catabolism and proteolysis The other one has threonine-type endopeptidase activity and the biological process category showed that is involved in immune system processes and proteolysis.

A first general analysis was carried out to classify and identify the functions corresponding to the proteins from each PPAT-CM using PANTHER classification system. CMT3 proteins were categorized in 8 molecular functions, 12 biological processes, 8 cellular components, 23 protein classes (Figure 2A, B, C, D). CM-T2 proteins were
Table III. Top ten proteins detected in conditioned media from periprostatic adipose tissue sorted according to their score.

CM-T3

\begin{tabular}{lc}
\hline Protein name & GN \\
\hline Isoform 10 of Fibronectin & FN1 \\
Isoform 2 of Filamin-A & FLNA \\
Fatty acid-binding protein, adipocyte & FABP4 \\
Hemoglobin subunit alpha & HBA1 \\
Isoform 4 of Myosin-11 & MYH11 \\
Neuroblast differentiation-associated protein & AHNAK \\
Spectrin alpha chain, non-erythrocytic 1 & SPTAN1 \\
Myosin-9 & MYH9 \\
Alpha-2-macroglobulin & A2M \\
Vimentin & VIM \\
CM-T2 & \\
\hline
\end{tabular}

\begin{tabular}{lc}
\hline Protein name & GN \\
\hline Spectrin alpha chain, non-erythrocytic 1 & SPTAN1 \\
Hemoglobin subunit alpha & HBA1 \\
Isoform 2 of Filamin-A & FLNA \\
Laminin subunit beta-2 & LAMB2 \\
Talin-1 & TLN1 \\
Serotransferrin & TF \\
Vimentin & VIM \\
Haptoglobin (Fragment) & HP \\
Hornerin & HRNR \\
Hemoglobin subunit delta & HBD \\
& \\
CM-BPH & \\
\hline Protein name & GN \\
\hline Alcohol dehydrogenase 1B & ADH1B \\
Fatty acid-binding protein, adipocyte & FABP4 \\
Isoform 2 of Collagen alpha-3(VI) chain & COL6A3 \\
Neuroblast differentiation-associated protein & AHNAK \\
Alpha-2-macroglobulin & A2M \\
Transketolase & TKT \\
Hemoglobin subunit alpha & HBA1 \\
Apolipoprotein A-I & APOA1 \\
Isoform 2 of Tropomyosin alpha-4 chain & TPM4 \\
Tropomyosin 1 (Alpha), isoform CRA_f & TPM1 \\
\hline
\end{tabular}

categorized in 6 molecular functions, 11 biological processes, 7 cellular components, 17 protein classes. CM$\mathrm{BPH}$ included 6 molecular functions, 10 biological processes, 7 cellular components, and 15 protein classes (Figure 2A, B, C, D). The GO analysis of proteins present in each $\mathrm{CM}$, without considering protein abundance, showed certain grade of similarity, except for the protein class, which showed more diversity in CM-T3 relative to CM-T2 and $\mathrm{CM}-\mathrm{BPH}$. These results are related to the fact that PPAT samples come all from, adipose tissue. 


\section{CM-T3 CM-T2 CM-BPH}

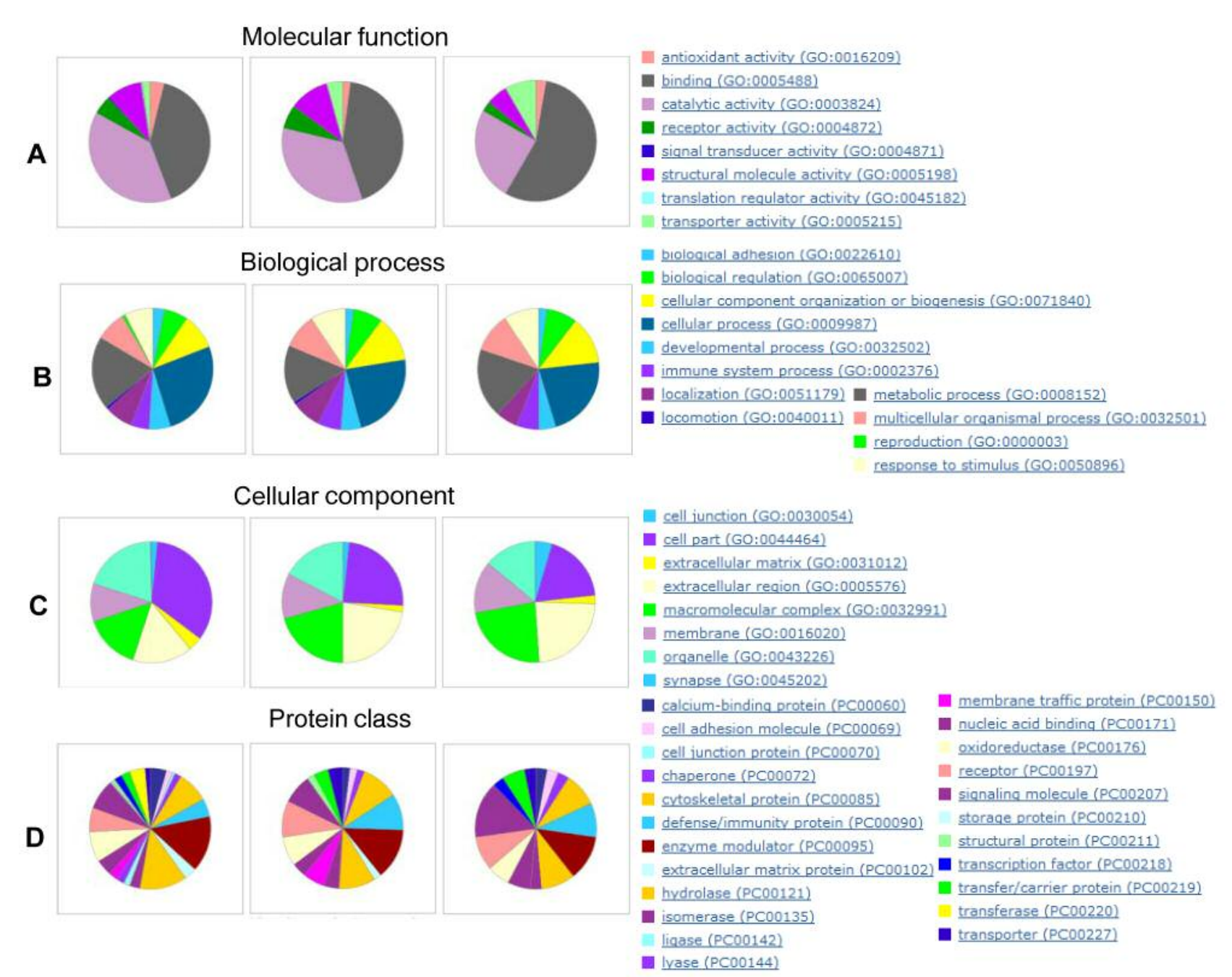

Figure 2. Protein categorization using the PANTHER classification system and annotated with ontology terms (GO). (A) Molecular functions, (B) Biological processes, (C) Cellular components, (D) Protein classes.

Catalytic activity, binding activity, structural molecule activity, receptor activity, transporter activity and antioxidant activity were common molecular functions reported for $\mathrm{CMs}$ proteins (Figure 2A). Binding activity was the main molecular function (Figure 2A) while cellular and metabolic were the main processes found in the category of biological process for all CMs (Figure 2B). Locomotion was a biological process associated with CM-T3 and CM-T2, while reproduction was associated to CM-T3 proteins (Figure 2B). Cell part was the main cellular component associated with CMs-T while macromolecular complex and extracellular region were for CM-BPH (Figure 2C). In terms of protein class, several annotations were specific to CM-T3 secretome, among them: cell junction proteins, ligases, lyases, storage proteins and transferases (Figure 2D). Extracellular matrix (ECM) and structural protein were associated to CMs-T while transcription factors were associated to $\mathrm{CM}-\mathrm{T} 3$ and CM-BPH proteins. ECM composition and remodeling are crucial for tumourigenesis and metastatic progression of cancer. Some of ECM proteins identified in CM-T3 were basement membrane-specific heparan sulfate proteoglycan core protein (HSPG2, linker protein), laminins (LAMA5, LAMA2, LAMB1 and LAMC1, linker proteins, protease inhibitor), latent-transforming growth factor beta-binding protein 1 (LTBP1, cell adhesion glycoprotein), EMILIN-1 (glycoprotein), fibrilin-1 (FBN1, cell adhesion glycoprotein), 
and spondin-1 (SPON1, glycoprotein). Laminin subunit beta2 (LAMB2) was detected in CMs-T.

In tumours that invade adjacent adipose tissue like ovarian cancer, up-regulation of genes encoding for fatty acid transport proteins, such as FABP4 and platelet glycoprotein 4 (CD36), as well as angiogenic genes like hematopoietic progenitor cell antigen CD34 (CD34) (49), was shown. Interestingly, these proteins were also detected in our adipose secretome. Adipocyte-derived FABPs are involved in cancer initiation and progression promoting homing, migration and invasion (50); FABP4 was detected in the three CMs and it was one of the top ten proteins in CM-T3; platelet glycoprotein 4 (CD36) and hematopoietic progenitor cell antigen (CD34) were detected only in CM-T3. Also, it was possible to detect epidermal fatty acid-binding protein (FABP5). FABP4 and FABP5 are expressed in macrophages and endothelial cells which are important contributors to adipose tissue and tumour microenvironment (51, 52). FABP4 has also an important role in adipocyte-mediated transport of lipids to prostate tumour cells as energy source for bone metastasis (53). FABP4 was found to be highly overexpressed in prostate skeletal tumours from obese mice and in bone metastasis samples from PCa patients, thus showing the importance of lipid trafficking in tumour metastasis and implicating FABP4 as a mediator of adipocyte-tumour cell interactions within the metastatic niche (53). Secretion of FABP4 responds to signals that induce lipolysis; this could be related to peritumoural adipose tissue and cancer associated adipoctyes (CAA), where lipolysis is enhanced and FABP4 could be released and have a paracrine action in tumoural tissue $(50,54)$. It is known that healthy life style lowers the risk of aggressive PCa. Lazaro et al. (55) observed that increasing aerobic physical activity decreased FABP4 plasma levels, independently of weight reduction, which would have a direct impact on cancer progression. FABP5 is involved in the uptake and transport of long chain fatty acids and plays a key role in cell signalling, gene regulation, cell growth and differentiation (56). The levels of circulating FABP5 in cancer are still unknown. FABP5 was found increased in PCa samples $(57,58)$ and its inhibition could inhibit tumourigenesis probably by reducing the expression of VEGF (57). These studies show that FABP4 and FABP5 could be useful as clinical markers and may prove a viable target to attack adipose tissue-related cancers.

Proteins related to cellular movement and migration were also detected. LGALS1, COL14A1 (detected in the three CMs), LAGLS3 and LGALS3BP (detected in CM-T3) are involved in the modulation of cell-cell and cell-matrix interactions and play a role in cancer-stroma interactions during the process of PCa metastasis (59). Vimentin (VIM) was within the top ten detected proteins in CMs-T. VIM was reported present in mesenchymal cells and related to adipocyte cell shape during adipogenesis contributing to both the formation of lipid droplets and the regulation of fatty acid transport through an interaction with FABP4 (21). Thus, VIM has a role in early and late stages of adipogenesis.

The detection of complement factors agrees with the emerging evidence that adipose tissue and adipocytes are a source of complement components, which have been proposed to be important in tissue maintenance and apoptosis $(60,61)$. Also, enrichment in complement genes was noted during adipocyte differentiation (62). Similarly, we observed eight complement genes in the secretome of CMs-T. Particularly, in CM-T3 C1QB, C1QC, C1S, C3, C5, C9 were detected and in CMs-T, C4A was also detected. The role of complement proteins in cancer growth is still unknown, but they are likely related to dysregulation of mitogenic signalling pathways, constant cellular proliferation, angiogenesis, resistance to apoptosis, and escape from the immune system (63).

PANTHER pathways analysis gave additional information. As expected, more pathways are associated with the secretomes of CMs-T (CM-T3: 67 pathways and CM-T2: 21 pathways) than CM-BPH (15 pathways). Table IV shows a list of pathways that involved at least 4 genes. Secreted proteins can act as ligands that engage specific receptors on the same cell, nearby cells, or distant cells and induce specific pathways. Proteins and pathways that are distinct or dysregulated in CMs$\mathrm{T}$ or in CM-BPH could be valuable as new biomarkers and therapeutic targets. Also, differences in the pathways related to secretome of CM-T3 or CM-T2 could be useful to determine biomarkers or drug targets in the different stages. Pathways with the highest number of genes identified in the three CMs were: integrin signalling pathway, chemokine mediated inflammation, cytokine signalling pathway and blood coagulation. On the other hand, pathways that involved CMs-T proteins were found in Parkinson disease, Huntington disease, B cell activation, FGF signalling pathway, cadherin signalling pathway, EGF receptor signalling pathway and 5-hydroxitryptamine degradation, some of them being known tumour related-pathways. It is noteworthy that other pathways induced by the proteins detected in CM-T3 were related to tumour signalling. Among those signalling pathway of apoptosis, angiogenesis, interleukin, VEGF, interferon gamma, TGF-beta, FAS, p38 MAPK, PI3 kinase, insulin/IGF-protein kinase B cascade, insulin/IGF-MAP kinase cascade, hypoxia response via HIF activation, vitamin D metabolism and pathway stood out. Among the proteins of CMT3 secretome involved in CCKR signalling map, the growthregulated alpha protein (CXCL1) and C-X-C motif chemokine 2 (CXCL2), matrix metalloproteinase-9 (MMP9), isoform 2 of plasminogen activator inhibitor 1 (SERPINE1), cAMPdependent protein kinase catalytic subunit beta (PRKACB), heat shock protein beta-1 (HSPB1), ELAV-like protein 1 (ELAVL1) and isoform 3 of tyrosine-protein phosphatase non-receptor type 11 (PTPN11), were detected. With respect to MMP-9, we have previously reported higher activity of proMMP-9 in CMs-T 
relative to $\mathrm{CM}-\mathrm{BPH}$ and that $\mathrm{CMs}-\mathrm{T}$ induced a significant increase of pro-MMP9 activity compared to CM-BPH in LNCaP cells (10). Likewise, CXCL1 and CXCL2 are important chemokines associated with inflammation, growth and tumour cancer progression (64). In a murine model of lung cancer, the secretome of cancer cells included a multitude of extracellular proteins that increased in co-cultures with cancer-associated fibroblasts or stromal cells; among these proteins, the chemokine CXCL1 was abundantly produced by cancer cells probably through paracrine signalling (65).

To identify proteins that are overrepresented in any functional class (referenced to human genome), the secretome of CMs were subjected to functional enrichment analysis using ProteiNSIDE and/or FunRich tools. The over-representation test calculates the probability that the number of differentially expressed genes belonging to a category is larger or smaller than that expected based on a reference using the binomial test. FunRich includes, exosomal and lysosomal proteins. It should be noted that dysregulation of the function of organelles like lysosomes, peroxisomes and endoplasmic reticulum (components of the metabolic network) is increasingly recognized in cancer cells. FunRich is a simple tool that allows comparison between two selected datasets. The top ten enriched GO annotations obtained with ProteINSIDE are listed in Table V. The most significantly enriched GO for CM-T3, CM-T2 and CM-BPH were extracellular exosomes ( $p$-value: $0,<0.001$ and $<0.001$ respectively) and extracellular region ( $p$ value $<0.001$ for all three). Also, CM-T3 secretome was enriched in focal adhesion $(p$-value $<0.001)$ and neutrophil degranulation proteins $(p$-value $<0.001)$. FunRich analysis also showed that exosomes was the most represented cellular component in the three CMs (CM-T3: 209 genes, 55.7\%, 5.2fold; CM-T2: 39 genes, 32\%, 62.9-fold and CM-BPH: 34 genes, 83\%, 7.8-fold) following by lysosomes (CM-T3: 165 genes, 44\%, 5.2-fold; CM-T2: 32 genes, 52\%, 6-fold and CMBPH: 25 genes, 61\%, 7.2-fold) (Figure 3A, B and C). Additionally, more than $80 \%$ of $\mathrm{CM}-\mathrm{BPH}$ proteins were exosomal while, the distribution in CMs-T, was more homogenous and other cellular compartments/organelles were represented (Figure 3D). Many proteins, lipids, DNA and RNA are packaged in exosomes and play an important role in cellto-cell communication (66). Exosomes carry a lot of cytoplasmic and nuclear proteins out of cell to target cells. Bioactive exosomal proteins can participate in cell proliferation, movement, migration and adhesion which can induce tumour metastasis. Exosomes may be capable of direct contribution to matrix remodeling both within the tumour microenvironment and potentially at distant sites away from the primary tumour. Previous reports showed that exosomal are essential to initiate a pre-metastatic niche in addition to soluble factors and contribute in the progression of cancer $(67,68)$.

We also made a selected molecular function gene enrichment analysis of the three CMs using FunRich tool
Table IV. Biological pathways associated with proteins of conditioned media from periprostatic adipose tissue involving at least 4 genes.

\begin{tabular}{|c|c|c|}
\hline $\mathrm{CM}$ & Pathway & \# Genes \\
\hline \multirow[t]{15}{*}{$\mathrm{T} 3$} & Integrin signalling pathway (P00034) & 25 \\
\hline & Inflammation mediated by chemokine and & \\
\hline & cytokine signaling pathway (P00031) & 15 \\
\hline & Parkinson disease (P00049) & 13 \\
\hline & Blood coagulation (P00011) & 12 \\
\hline & Cytoskeletal regulation by Rho GTPase (P00016) & 9 \\
\hline & $\begin{array}{l}\text { Nicotinic acetylcholine receptor signaling } \\
\text { pathway (P00044) }\end{array}$ & 9 \\
\hline & Plasminogen activating cascade (P00050) & 8 \\
\hline & CCKR signaling map (P06959) & 8 \\
\hline & Glycolysis (P00024) & 7 \\
\hline & Alzheimer disease-presenilin pathway (P00004) & 5 \\
\hline & $\begin{array}{l}\text { Gonadotropin-releasing hormone receptor } \\
\text { pathway (P06664) }\end{array}$ & 5 \\
\hline & Huntington disease (P00029) & 4 \\
\hline & Wnt signaling pathway (P00057) & 4 \\
\hline & FGF signaling pathway (P00021) & 4 \\
\hline \multirow[t]{3}{*}{$\mathrm{T} 2$} & Integrin signalling pathway (P00034) & 7 \\
\hline & Blood coagulation (P00011) & 5 \\
\hline & $\begin{array}{l}\text { Inflammation mediated by chemokine and } \\
\text { cytokine signaling pathway (P00031) }\end{array}$ & 4 \\
\hline \multirow[t]{2}{*}{$\mathrm{BPH}$} & Integrin signalling pathway (P00034) & 7 \\
\hline & Blood coagulation (P00011) & 5 \\
\hline
\end{tabular}

(Figure 3E). This analysis showed that only CM-T3 was significantly enriched in enzymes (25 genes, 6.7\%, 2.4-fold, $p$-value $<0.001$ ), structural molecules (13 genes, $3.5 \%, 2.5$ fold, $p$-value $=0.04)$, calcium ion binding proteins $(12$ genes, $3.2 \%, 3.3$-fold, $p$-value $<0.001$ ), chaperons ( 9 genes, $2.4 \%, 3.7$ fold, $\mathrm{p}$-value $=0.02$ ) and complement proteins ( 7 genes, $1.9 \%$, 12.9-fold, $p$-value $=0.02)$. Defense/immunity proteins were enriched in CM-T2 (4 genes, 6.4\%, 20.4-fold, $p$-value=0.005). Analysis of biological processes indicated that cell growth and/or maintenance proteins were the most significantly enriched in the three CMs (CM-T3: 84 genes, 22.4\%, 3.8-fold, $p$-value $<0.001$; CM-T2: 20 genes, 32.3\%, 5.5-fold, $p$-value<0.001; CM-BPH: 14 genes, 34.1\%, 5.8-fold, $p$-value $<0.001)$. The biological process proteins that were significantly represented in CM-T3 secretome included protein metabolism (60 genes, 16\%, 2.3-fold, $p$-value $<0.001$ ), general metabolism (63 genes, 16.8\%, 1.9-fold, $p$-value $<0.001$ and energy pathways (62 genes, $16.5 \%, 1.9$-fold, $p$-value $<0.001)$. Immune response proteins were represented in CM-T3 (24 genes, 6.4\%, 2.1-fold, $p$-value=0.015) and CM-T2 ( 5 genes, $8 \%, 2.7$-fold, $p$-value=0.04), while transport proteins were enriched $(p$-value $=0.04)$ in CM-T2 $(8$ genes, $13 \%, 20$-fold $)$ and CM-BPH (6 genes, 14.6\%, 2.3-fold) secretomes (Figure 3F).

A complementary analysis was performed to determine enrichment or depletion at the GO molecular function level during PCa progression. Dataset of CM-T3 or CM-T2 were compared to CM-BPH (Figure 4A and B, respectively) and 
Table V. ProteINSIDE gene enrichment analysis. List of top ten multiple annotations GOs for each conditioned media from periprostatic adipose tissue.

\begin{tabular}{|c|c|c|c|c|c|c|}
\hline $\mathrm{CM}$ & GO number & Function & GO & $\begin{array}{c}\text { Count } \\
\text { of protein }\end{array}$ & $\begin{array}{c}\text { GO frequency } \\
\text { within the dataset (\%) }\end{array}$ & $\begin{array}{c}p \text {-Value } \\
\text { BH }\end{array}$ \\
\hline \multirow{10}{*}{$\mathrm{T} 3$} & GO:0070062 & Extracellular exosome & $\mathrm{CC}$ & 272 & 66.5 & 0 \\
\hline & GO:0005576 & Extracellular region & $\mathrm{CC}$ & 174 & 42.5 & $7.62 \mathrm{E}-183$ \\
\hline & GO:0005515 & Protein binding & MF & 256 & 62.6 & $2.79 \mathrm{E}-174$ \\
\hline & GO:0005615 & Extracellular space & $\mathrm{CC}$ & 136 & 33.3 & $1.28 \mathrm{E}-144$ \\
\hline & GO:0005829 & Cytosol & $\mathrm{CC}$ & 176 & 43 & $4.63 \mathrm{E}-119$ \\
\hline & GO:0072562 & Blood microparticle & $\mathrm{CC}$ & 64 & 15.7 & $4.67 \mathrm{E}-103$ \\
\hline & GO:0031012 & Extracellular matrix & $\mathrm{CC}$ & 75 & 18.3 & $4.13 \mathrm{E}-100$ \\
\hline & GO:0005925 & Focal adhesion & $\mathrm{CC}$ & 56 & 13.7 & 7.83E-71 \\
\hline & GO:0043312 & Neutrophil degranulation & BP & 59 & 14.4 & $1.73 \mathrm{E}-70$ \\
\hline & GO:0002576 & Platelet degranulation & $\mathrm{BP}$ & 41 & 10 & $3.90 \mathrm{E}-65$ \\
\hline \multirow[t]{10}{*}{$\mathrm{T} 2$} & GO:0070062 & Extracellular exosome & $\mathrm{CC}$ & 57 & 81.4 & $2.61 \mathrm{E}-62$ \\
\hline & GO:0005576 & Extracellular region & $\mathrm{CC}$ & 39 & 55.7 & $1.39 \mathrm{E}-44$ \\
\hline & GO:0072562 & Blood microparticle & $\mathrm{CC}$ & 21 & 30 & $1.35 \mathrm{E}-39$ \\
\hline & GO:0005615 & Extracellular space & $\mathrm{CC}$ & 30 & 42.9 & $1.10 \mathrm{E}-34$ \\
\hline & GO:0005515 & Protein binding & MF & 47 & 67.1 & $4.84 \mathrm{E}-33$ \\
\hline & GO:0002576 & Platelet degranulation & $\mathrm{BP}$ & 14 & 20 & $2.07 \mathrm{E}-26$ \\
\hline & GO:0005829 & Cytosol & $\mathrm{CC}$ & 35 & 50 & $1.99 \mathrm{E}-25$ \\
\hline & GO:0031012 & Extracellular matrix & $\mathrm{CC}$ & 17 & 24.3 & $8.22 \mathrm{E}-25$ \\
\hline & GO:0005788 & Endoplasmic reticulum lumen & $\mathrm{CC}$ & 14 & 20 & $1.81 \mathrm{E}-21$ \\
\hline & GO:0005200 & Structural constituent of cytoskeleton & MF & 10 & 45 & $3.45 \mathrm{E}-18$ \\
\hline \multirow[t]{10}{*}{ BPH } & GO:0070062 & Extracellular exosome & $\mathrm{CC}$ & 41 & 89.1 & $9.52 \mathrm{E}-46$ \\
\hline & GO:0005576 & Extracellular region & $\mathrm{CC}$ & 30 & 65.2 & $9.21 \mathrm{E}-36$ \\
\hline & GO:0072562 & Blood microparticle & $\mathrm{CC}$ & 15 & 32.6 & $1.06 \mathrm{E}-28$ \\
\hline & GO:0002576 & Platelet degranulation & BP & 14 & 30.4 & $1.31 \mathrm{E}-28$ \\
\hline & GO:0005615 & Extracellular space & $\mathrm{CC}$ & 23 & 50 & 7.04E-28 \\
\hline & GO:0031012 & Extracellular matrix & $\mathrm{CC}$ & 16 & 34.8 & $1.79 \mathrm{E}-25$ \\
\hline & GO:0005515 & Protein binding & MF & 32 & 69.6 & $6.45 \mathrm{E}-23$ \\
\hline & GO:0031093 & Platelet alpha granule lumen & $\mathrm{CC}$ & 10 & 21.7 & $8.96 \mathrm{E}-22$ \\
\hline & GO:0005829 & Cytosol & $\mathrm{CC}$ & 26 & 56.5 & $5.08 \mathrm{E}-20$ \\
\hline & GO:0005788 & Endoplasmic reticulum lumen & $\mathrm{CC}$ & 12 & 17.39 & $5.98 \mathrm{E}-11$ \\
\hline
\end{tabular}

also between the two stages (T3 and T2) of PCa (Figure 4C). According to the molecular functions, CM-T3 secretome was enriched (compared to CM-BPH) in ubiquitin specific proteins (87.6-fold), complement proteins (76.7-fold), transcription regulators and oxidoreductase (65.7-fold), RNA and DNA binding proteins (54.8-fold and 43.9, respectively), serine-type peptidases, defense/immunity proteins (43.9-fold), chemokines (32.9-fold), metallopeptidases (22-fold) and cell adhesion molecules (1.3-fold). Contrarily, the CM-T3 secretome was depleted from heat shock proteins (4.6-fold), binding proteins (3.4-fold), translation regulators, receptors and transporters (3.1-fold), and structural constituents of cytoskeleton (2.3fold) (Figure 4A). The CM-T2 secretome was enriched (compared to CM-BPH) in defense/immunity proteins (265.2fold), peptidases and receptor signalling complexes and scaffold activity (132.9-fold); transcription factors complement proteins, RNA binding proteins, ubiquitin specific proteases, aldehyde dehydrogenases and superoxide dismutase (all 66.5fold) (Figure 5B). By contrast, the CM-T2 secretome was depleted from heat shock proteins, translation regulators and peroxidases (152.7-fold) and protein binding (4.5 fold) (Figure 4B). Comparison between the two stages of PCa showed that CM-T3 secretome was enriched (compared to CM-T2) in transcription regulators and oxidoreductases (99.4-fold), peroxidases (82.8-fold), serine-type peptidases, DNA binding (66.3-fold), chemokines and ATPases (49.8-fold), metallopeptidases, complement proteins and heat shock proteins (33.3-fold change), glutathione transferases and growth factors (16.7-fold) (Figure 4C). By contrast, the CMT3 secretome was depleted from transcription factors (300fold), peptidases and defense/immunity proteins (6.0-fold), superoxide dismutases, structural constituents of cytoskeleton and aldehyde dehydrogenases (3.0-fold), transporter (2.7-fold), receptor signalling complexes and scaffold proteins (2.4-fold), receptor binding and activity (2.0-fold) (Figure 4C). With respect to biological processes $\mathrm{GO}, \mathrm{CM}-\mathrm{T} 3$ secretome was enriched (compared to $\mathrm{CM}-\mathrm{BPH}$ ) in cytoskeleton organization and biogenesis proteins (32.9-fold), apoptosis and regulation 
A percentage $\rightarrow-\log 10$ ( $p$-value) $\rightarrow-p=0.05$ reference

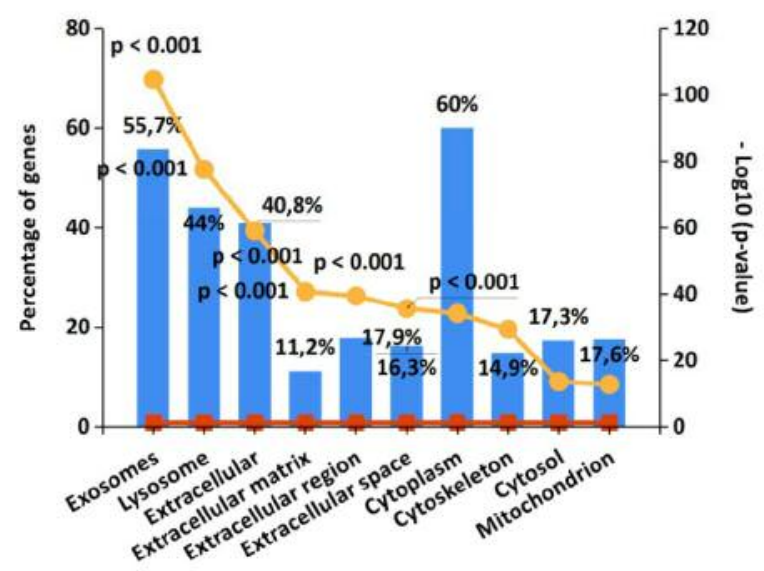

C

percentage $\rightarrow-\log 10$ ( $p$-value) $\rightarrow-p=0.05$ reference
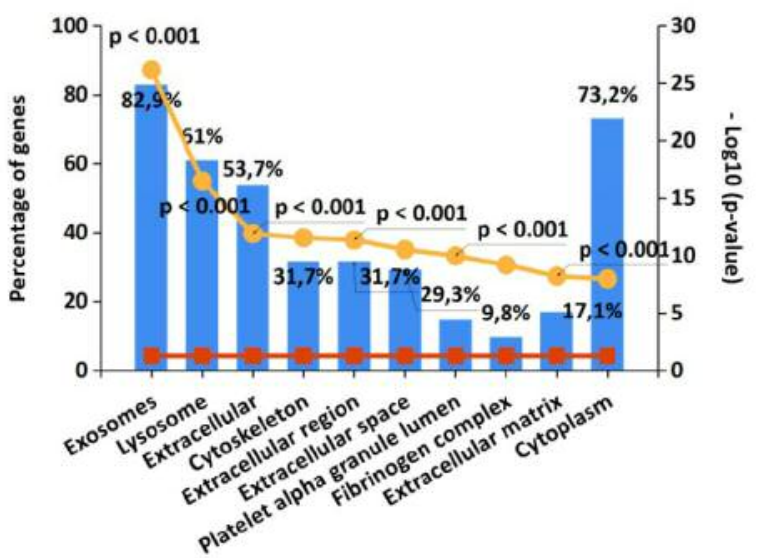

Cellular component

$\mathbf{E}$

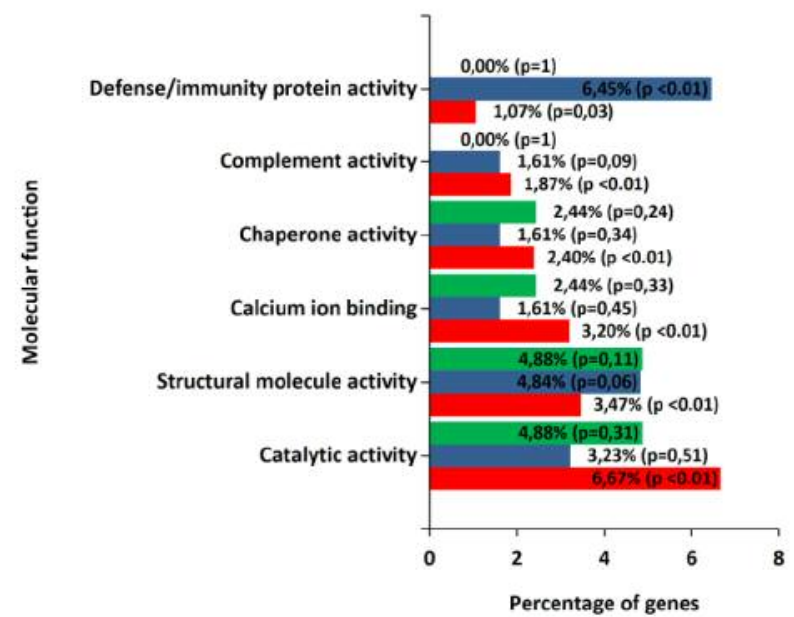

B
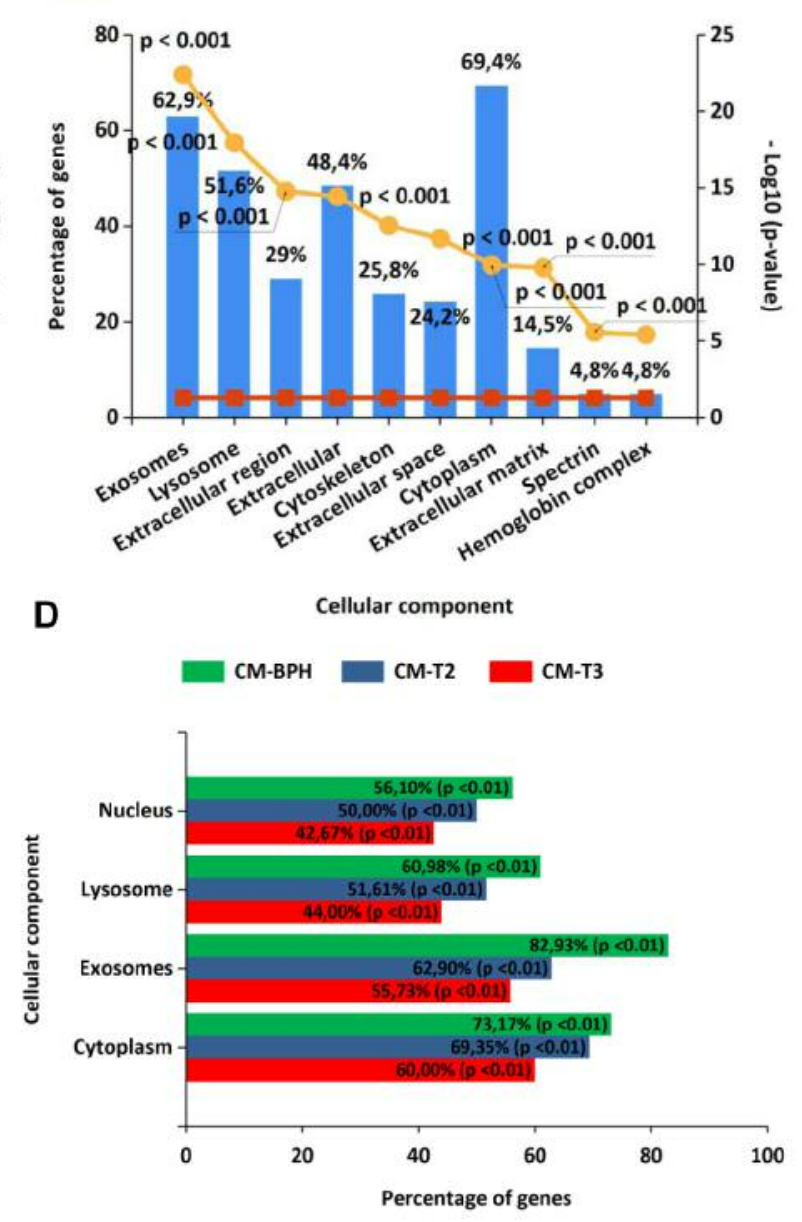

$\mathbf{F}$

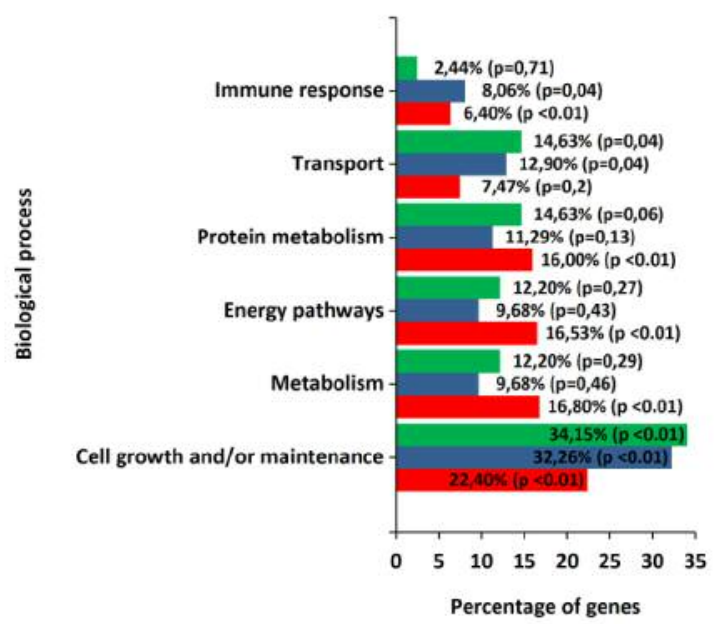

Figure 3. Column charts of the subcellular localization of proteins. A) CM-T3. B) CM-T2. C) CM-BPH. Bar chart of represented cellular compartments (D); molecular functions (E) and biological processes (F), according to FunRich analysis. 

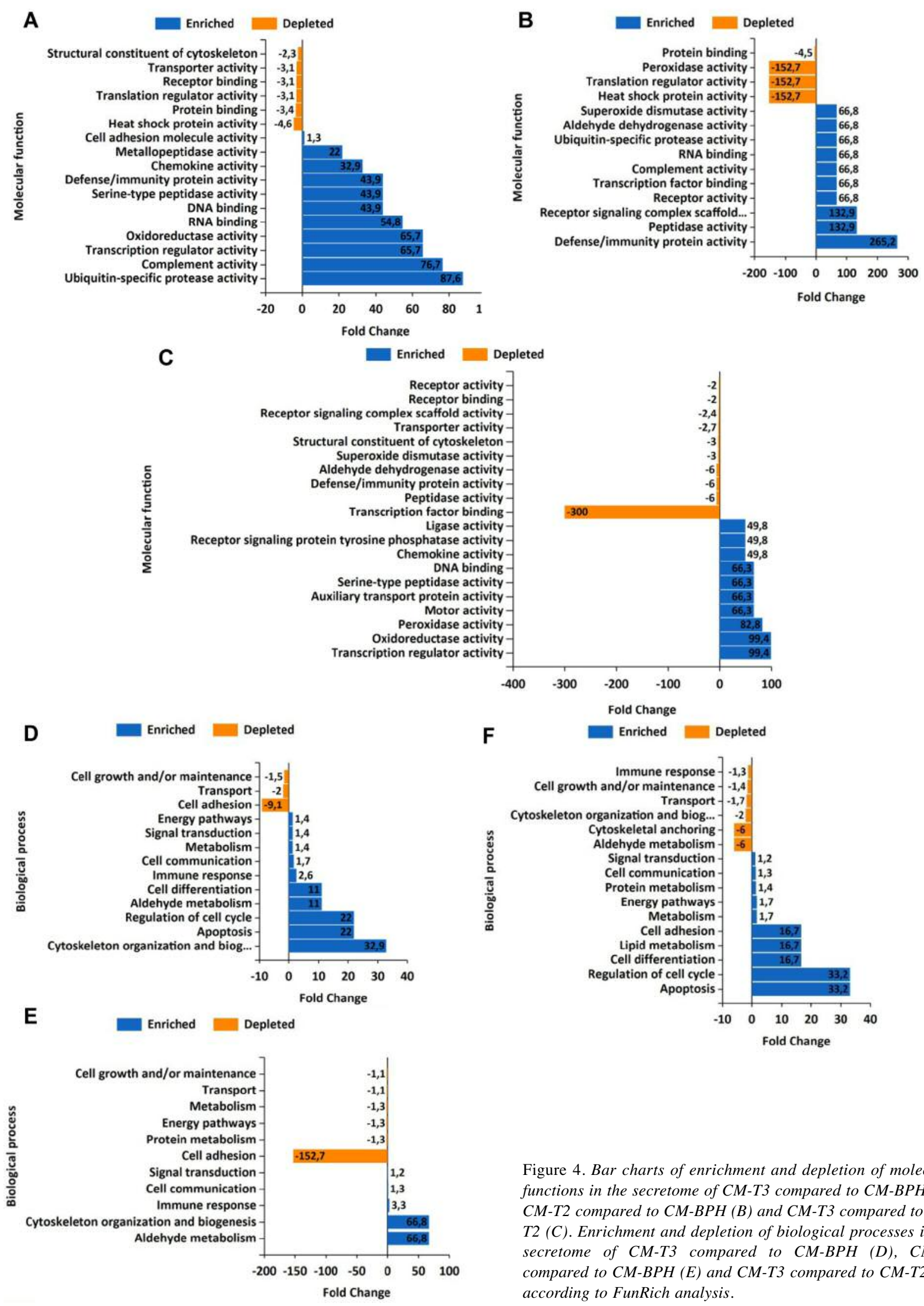

Depleted
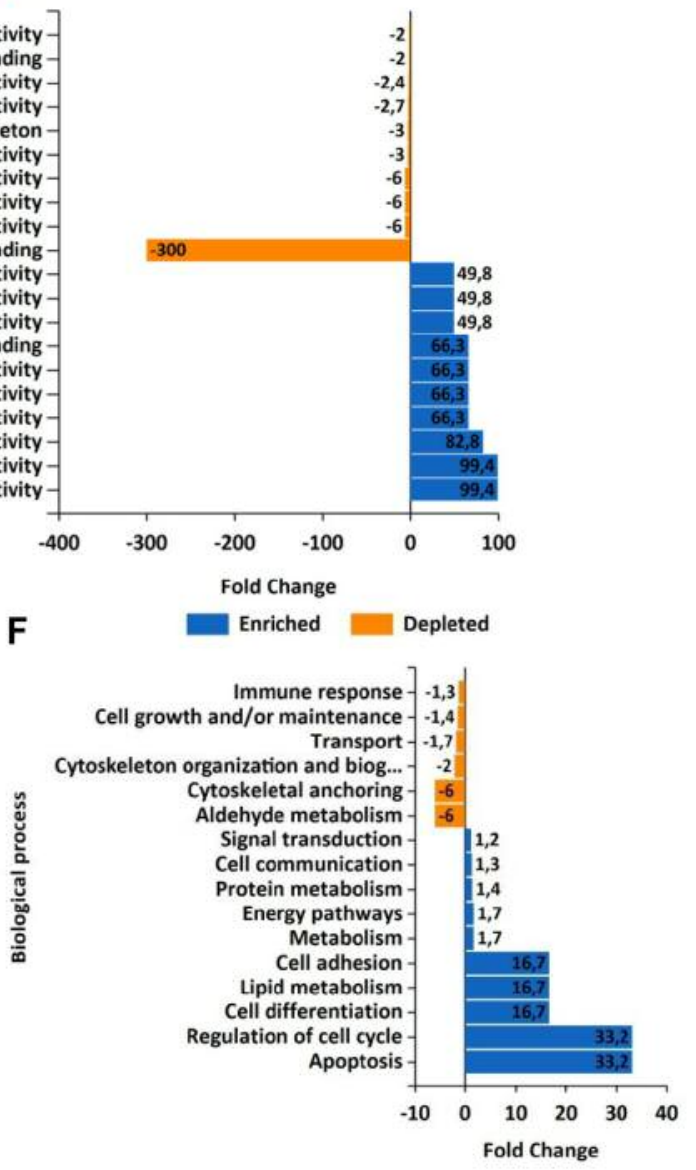

Figure 4. Bar charts of enrichment and depletion of molecular functions in the secretome of CM-T3 compared to CM-BPH (A); $C M-T 2$ compared to $C M-B P H(B)$ and CM-T3 compared to CM$T 2(C)$. Enrichment and depletion of biological processes in the secretome of CM-T3 compared to CM-BPH (D), CM-T2 compared to CM-BPH (E) and CM-T3 compared to CM-T2 (F), according to FunRich analysis. 
of cell cycle proteins (22-fold), aldehyde metabolism and cell differentiation proteins (11-fold), immune response proteins (2.6-fold), signal transduction and energy pathway proteins (1.4-fold) (Figure 4D). By contrast, the CM-T3 secretome was depleted in cell communication proteins (1.7-fold), cell adhesion molecules (9.1-fold), transport (2-fold) and cell growth and/or maintenance (1.5-fold) (Figure 4D). CM-T2 secretome was enriched (compared to CM-BPH) in aldehyde metabolism (66.8-fold), cytoskeleton organization and biogenesis (66.8-fold), immune response (3.3-fold), cell communication (1.3-fold), signal transduction (1.2-fold) proteins (Figure 4E). By contrast, it was depleted in cell adhesion (152.7-fold), protein metabolism, energy pathways and metabolism (1.3-fold), transport and cell growth and/or maintenance (1.1-fold) proteins (Figure 4E). Furthermore, CM-T3 secretome was enriched (compared to CM-T2) in apoptosis and regulation of the cell cycle (33.2-fold), cell differentiation, lipid metabolism and cell adhesion (16.7-fold), metabolism and energy pathways (1.7-fold), protein metabolism (1.4-fold), cell communication (1.3-fold) and signal transduction (1.2-fold) proteins (Figure 4F). By contrast, CM-T3 secretome was depleted (compared to CMT2) in aldehyde metabolism and cytoskeletal anchoring (6.0fold), cytoskeleton organization and biogenesis (2.0-fold), transport (1.7-fold), cell growth and/or maintenance (1.4-fold) and immune response (1.4-fold) proteins (Figure 4F).

The top ten enriched biological pathways for each CMs are shown in Table VI. The integrin family cell surface interaction was the more enriched pathway for CM-T3 (80 genes, $p$-value $<0.001)$, homeostasis pathway was for CM-T2 (11 genes, $p$-value $<0.001$ ) and TRAIL signalling pathway was for CM-BPH (15 genes, $p$-value<0.001) (Table VI). Some significantly enriched pathways exclusive for the CMs-T are shown in Figure 5A and B. These include: Immune system, adaptive immune system, L1CAM interactions, NCAM signalling for neurite out-growth, complement cascade, costimulation by the CD28 family, CD28 co-stimulation, initial triggering of complement, CD28 dependent Vav1 pathway and interaction between L1 and Ankyrins (Figure 5A). Proteins of the spectrin family (SPTA1, SPTAN1 and SPTBN1), talin1 (TLN1) and complement 4 (C4) were common proteins to this set of biological pathways. TLN1 is a focal adhesion complex protein that regulates integrin interactions with the ECM and is up-regulated during adipogenesis (69). Their overexpression enhanced PCa cell adhesion, migration and invasion by activating survival signals and conferring resistance to anoikis (70). Other proteins involved in these pathways were laminins (LAMB1, LAMC1), proteins of complement family (C1QB, C1QC, C3, C5, C9), proteasome subunits (PSMA1, PSMA5, PSMA6, PSMA7, PSMB1, PSMB4, PSMB5), 14-3-3 protein gamma (YWHAG and YWHAZ) and several cell adhesion molecules. NCAM pathway is induced by cell adhesion molecules like neural cell adhesion molecule 1 (NCAM1) and cadherins. Loss of NCAM function during tumour progression affects cell-matrix adhesion and integrin-mediated cell-matrix adhesion (71). Some other detected cell adhesion molecules of this pathways were tyrosine-protein phosphatase non-receptor type 11 (PTPN11) that mediate signal transduction and promote adipogenesis (72); isoform Delta14-15 of platelet endothelial cell adhesion molecule (PECAM1/CD31) involved in angiogenesis (73). On the other hand, regulation of cytoskeletal remodeling and cell spreading by IPP complex components was the most enriched pathway in CM-T3 and CM-BPH. Pathways exclusively enriched in CM-T3 secretome are shown in Figure 5B. Pathways related to metabolism were aspartate degradation II and TCA cycle variation III (eukaryotic) through malate dehydrogenase cytoplasmic (MDH1), malate dehydrogenase (MDH2), aspartate aminotransferase (GOT1) and cytoplasmic aconitate hydratase (ACO1) proteins. MDH2 expression was reported to be elevated in PCa cell lines compared to BPH epithelial cells and that it regulates chemotherapy-induced signal transduction and oxidative metabolism (74). The metabolic pathway of particular interest was that related with Warburg effect and through pyruvate fermentation to lactate (pvalue 0.03 ) allows rapid biosynthesis to support growth and proliferation of cancer cells. This pathway represented by Llactate dehydrogenase B chain (LDHB) and isoform 4 of Llactate dehydrogenase A chain (LDHA). Pathways associated to immune system were also enriched, C3 and C5 proteins, alternative complement activation, classical antibody-mediated complement activation and Interleukin-3, 5 and GM-CSF signalling. Regarding advanced glycosylation endproduct receptor (RAGE) signalling three proteins were detected in CMT3: f-actin-capping protein subunit alpha-2 (CAPZA2), isoform 2 of glucosidase 2 subunit beta (PRKCSH, substrate for protein kinase C) and protein S100-B (S100B). Advanced glycation end products (AGE) derived from endogenous nonenzymatic glycation and AGE-associated signalling pathways play a key role in aging-dependent adiposity through the pro-adipogenic function of senescent preadipocytes (75). Interestingly, it has recently been shown that RAGE pathway may play a role in malignant transformation of MSCs, and that this process may be mediated through S100B. Glioma-conditioned medium and recombinant S100B increased RAGE and its downstream Akt1, STAT3 genes expression as well as phosphorylation and transcriptional activation (76).

Additional FunRich analysis was carried out to get information about sites of protein expression (Figure 5C and D). The analysis showed that most of proteins in $\mathrm{CMs}$ are plasma proteins (CM-BPH and CM-T2 100\%, CM-T3 94\%); the percentage of serum proteins decreased as disease becomes more malignant (CM-BPH 95\%, CM-T2 90\% and CM-T3 80\%) (Figure 5C). Thus, CMs-T would have higher percentage of coagulation factors genes (CM-T3 14\%, CM$\mathrm{T} 2$ 10\%) relative to benign disease (CM-BPH 5\%). Accumulating evidence indicates the potential interaction of 
A A
CM-T2

CM-T3

Interaction between L1 and Ankyrins -

CD28 dependent Vav1 pathway-

Initial triggering of complement

CD28 co-stimulation

Costimulation by the $\mathrm{CD} 28$ family

NCAM signaling for neurite out-growth

Complement cascade -

ICAM interaction

Axon guidance

Adaptive Immune System

Immune System -

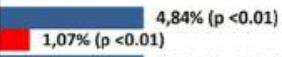

$1,07 \%$ (p

$1,33 \%(p<0.01)$

$1,60 \%(p<0.01)$

$1,60 \%(p<0.01)$

$1,87 \%(p<0.01)$

$2,13 \%(p<0.01)$

$3,23 \%(p<0.01)$

(p)

6,45\% 2 (p< $<0.01)$

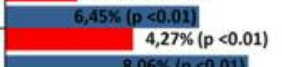

$\begin{array}{r}4,27 \%(p<0.01) \\ \hline 8,06 \%(p<0.01)\end{array}$

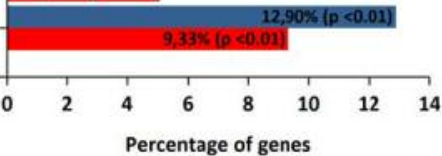

C

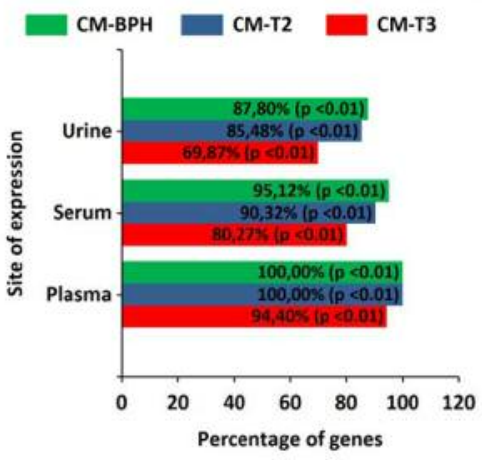

E

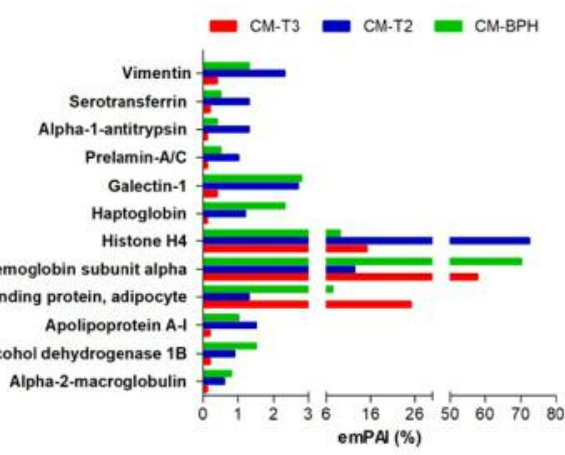

G

- $\mathrm{CM}-\mathrm{BPH}=\mathrm{CM}-\mathrm{T} 3$

Tropomyosin 1 (Alpha), isoform CRA Transketolase Transketolase
Ras suppressor protein 1 Ribonuclease inhibitor Phosphoglucomutase-1

Junction plakoglobin Immunoglobulin lambda constant 2 Immunoglobulin kappa constant Immunoglobulin heavy constant gamma 3 (Fragment) Profilin-1 $=$

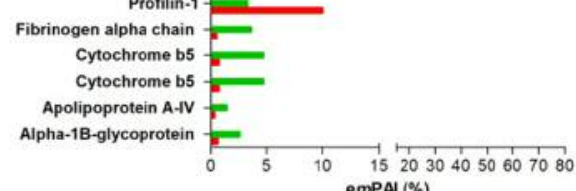
emPA $(\%)$
B

$\mathrm{CM}-\mathrm{T3}$

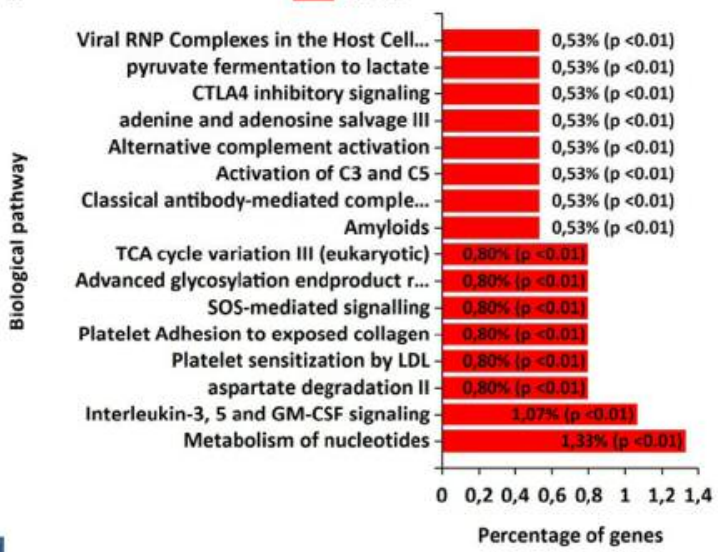

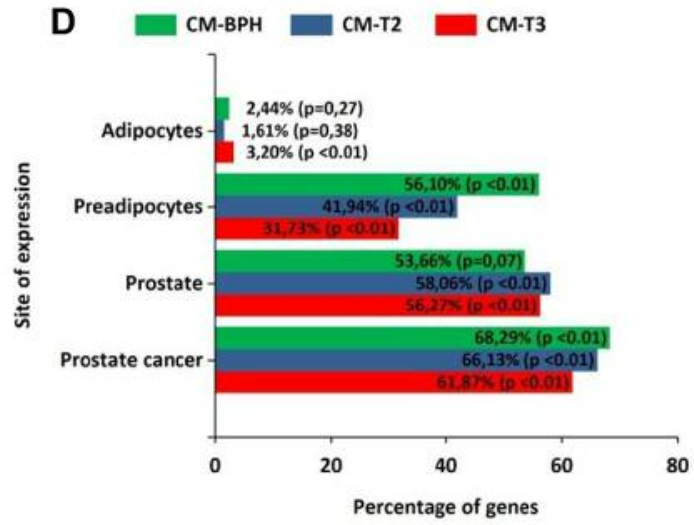

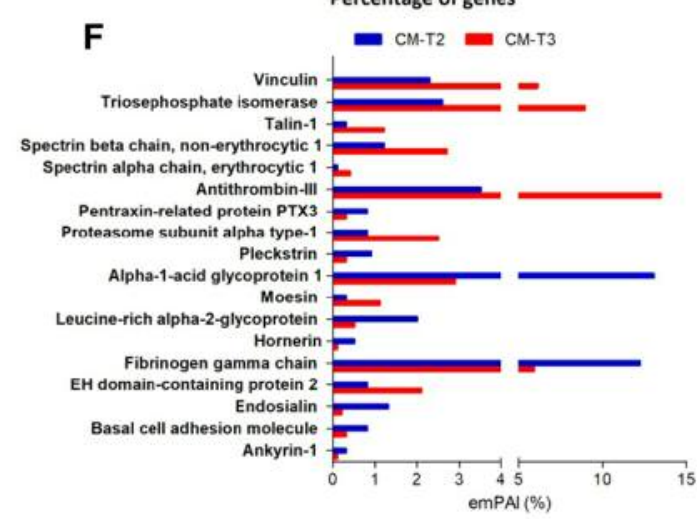

Figure 5. Bar charts of exclusive enriched biological pathways for $C M s-T$ (A) and for CM-T3 (B). Bar charts of sites of protein expression $(C$ and $D)$. Bar charts of relative exponentially modified protein abundance index (emPAI) with at least two-fold change. (E) Between CM-T3, CM-T2 and CM-BPH; $(F)$ between $C M-T 2$ and CM-T3; $(G)$ between $C M-T 3$ and $C M-B P H$, according FunRich analysis. 
Table VI. Top ten enriched biological pathways for conditioned media from periprostatic adipose tissue according to FunRich analysis.

\begin{tabular}{|c|c|c|c|c|}
\hline Top ten enriched biological pathways & \# Genes & $\%$ Genes & Fold enrichment & $p$-Value $\mathrm{BH}$ method \\
\hline \multicolumn{5}{|l|}{ CM-T3 } \\
\hline Integrin family cell surface interactions & 80 & 21.3 & 3.0 & $6.7 \mathrm{E}-16$ \\
\hline Hemostasis & 40 & 10.7 & 5.5 & $1.1 \mathrm{E}-15$ \\
\hline Beta1 integrin cell surface interactions & 78 & 20.8 & 3.0 & $1.1 \mathrm{E}-15$ \\
\hline Integrin cell surface interactions & 18 & 4.8 & 12.8 & $7.3 \mathrm{E}-13$ \\
\hline Beta3 integrin cell surface interactions & 14 & 3.7 & 16.7 & $1.4 \mathrm{E}-11$ \\
\hline TRAIL signaling pathway & 68 & 18.1 & 2.6 & $4.0 \mathrm{E}-11$ \\
\hline Epithelial-to-mesenchymal transition & 24 & 6.4 & 6.7 & $5.3 \mathrm{E}-11$ \\
\hline Proteoglycan syndecan-mediated signaling events & 68 & 18.1 & 2.6 & $5.2 \mathrm{E}-11$ \\
\hline Cell-Cell communication & 19 & 5.1 & 8.3 & $2.3 \mathrm{E}-10$ \\
\hline Syndecan-1-mediated signaling events & 65 & 17.3 & 2.6 & $2.5 \mathrm{E}-10$ \\
\hline \multicolumn{5}{|l|}{ CM-T2 } \\
\hline Hemostasis & 11 & 17.7 & 9.1 & $1.6 \mathrm{E}-05$ \\
\hline Platelet degranulation & 5 & 8.1 & 55.5 & $1.6 \mathrm{E}-05$ \\
\hline Muscle contraction & 6 & 9.7 & 31.3 & $1.6 \mathrm{E}-05$ \\
\hline Response to elevated platelet cytosolic $\mathrm{Ca}^{2+}$ & 5 & 8.1 & 39.8 & $5.2 \mathrm{E}-05$ \\
\hline Apoptotic cleavage of cellular proteins & 5 & 8.1 & 39.8 & $5.2 \mathrm{E}-05$ \\
\hline Apoptotic execution phase & 5 & 8.1 & 32.4 & 0.0001 \\
\hline Apoptosis & 7 & 11.3 & 13.8 & 0.0002 \\
\hline Smooth Muscle Contraction & 4 & 6.5 & 51.8 & 0.0002 \\
\hline Formation of Fibrin Clot (Clotting Cascade) & 4 & 6.5 & 37.7 & 0.0007 \\
\hline Caspase-mediated cleavage of cytoskeletal proteins & 3 & 4.8 & 84.8 & 0.0009 \\
\hline \multicolumn{5}{|l|}{$\mathrm{CM}-\mathrm{BPH}$} \\
\hline TRAIL signaling pathway & 15 & 36.6 & 5.3 & 2.7E-05 \\
\hline Integrin family cell surface interactions & 15 & 36.6 & 5.1 & $2.7 \mathrm{E}-05$ \\
\hline Beta1 integrin cell surface interactions & 15 & 36.6 & 5.2 & 2.7E-05 \\
\hline Proteoglycan syndecan-mediated signaling events & 15 & 36.6 & 5.2 & 2.7E-05 \\
\hline Epithelial-to-mesenchymal transition & 7 & 17.1 & 17.8 & $3.9 \mathrm{E}-05$ \\
\hline Hemostasis & 8 & 19.5 & 10.0 & 7.3E-05 \\
\hline Syndecan-1-mediated signaling events & 13 & 31.7 & 4.7 & 7.3E-05 \\
\hline Glypican pathway & 14 & 34.1 & 4.9 & $7.3 \mathrm{E}-05$ \\
\hline GMCSF-mediated signaling events & 13 & 31.7 & 4.7 & 7.3E-05 \\
\hline Insulin Pathway & 13 & 31.7 & 4.7 & 7.3E-05 \\
\hline
\end{tabular}

BH: Benjamini-Hochberg.

the coagulation system and malignant processes, suggesting a state of hypercoagulability when cancer is present (77). However, the exact mechanisms by which coagulation proteins promote tumourigenesis are not fully understood, and are likely related to peritumoural deposition of fibrin and to alteration of homeostatic factors, hence favoring proliferation, angiogenesis and metastasis (78). Also, it has been reported that the thrombin-antithrombin complex was associated with Gleason score and fibrinogen with higher tumour stages (II-IV) (79).

On the other hand, urine represents a non-invasive and important source of biomarkers for the early detection of $\mathrm{PCa}$ since it contains secreted prostatic products and exfoliated tumour cells. A significant percentage of CM-BPH and CM-T2 proteins were found in urine (86 and $88 \%$ respectively) relative to $\mathrm{CM}-\mathrm{T} 3(70 \%)$ (Figure $5 \mathrm{C}$ ).

During their interaction with cancer cells, adipocytes can dedifferentiate into pre-adipocytes or being reprogrammed
Table VII. Number of potentially secreted proteins from conditioned media as predicted for classical and non-classical pathways according to ProteinINSIDE tool.

\begin{tabular}{lccc}
\hline CM & \# Proteins & $\begin{array}{c}\text { Classical pathway } \\
\text { \# Proteins }\end{array}$ & $\begin{array}{c}\text { Non-classical pathway } \\
\text { \# Proteins }\end{array}$ \\
\hline T3 & 563 & $150(27 \%)$ & $169(30 \%)$ \\
T2 & 78 & $29(37 \%)$ & $33(42 \%)$ \\
BPH & 52 & $17(33 \%)$ & $21(42 \%)$ \\
\hline
\end{tabular}

into cancer-associated adipocytes (CAA). There was a significant percentage of genes expressed in preadipocytes (CM-T3 32\%, CM-T2 42\% and CM-BPH 56\%) and their percentage diminished as disease advanced, but no statistical difference was found in the percentage of adipocyte proteins expressed in CM-T2 and CM-BPH while it was significant 
Table VIII. List of proteins secreted by classical pathways according to ProteINSIDE tool.

\begin{tabular}{|c|c|c|c|}
\hline $\mathrm{CM}$ & Biological process & GN & Molecular function \\
\hline \multirow[t]{58}{*}{ T3 } & Cell growth and/or maintenance & & \\
\hline & Isoform 2 of Laminin subunit alpha- 4 & LAMA4 & Cell adhesion molecule activity \\
\hline & Laminin subunit alpha-5 & LAMA5 & $"$ \\
\hline & Cadherin-5 (Fragment) & CDH5 & $"$ \\
\hline & Isoform 3 of Cadherin-13 & CDH13 & $"$ \\
\hline & Prolargin & PRELP & Cytoskeletal anchoring activity \\
\hline & Basement membrane-specific & & \\
\hline & heparan sulfate proteoglycan core protein & HSPG2 & ECM structural constituent \\
\hline & Laminin subunit gamma-1 & LAMC1 & $"$ \\
\hline & Laminin subunit beta- 1 & LAMB1 & $"$ \\
\hline & Lumican & LUM & $"$ \\
\hline & Isoform 4 of Collagen alpha-1(XII) chain & COL12A1 & $"$ \\
\hline & Isoform 2 of Nidogen- 1 & NID1 & $"$ \\
\hline & Collagen alpha-2(VI) chain & COL6A2 & " \\
\hline & EMILIN-1 & EMILIN1 & $"$ \\
\hline & Laminin subunit alpha-2 & LAMA2 & $"$ \\
\hline & Extracellular matrix protein 1 & ECM1 & $"$ \\
\hline & Collagen alpha-2(I) chain & COL1A2 & $"$ \\
\hline & Vitronectin & VTN & $"$ \\
\hline & Spondin-1 & SPON1 & $"$ \\
\hline & Fibrillin-1 & FBN1 & $"$ \\
\hline & Procollagen C-endopeptidase enhancer 1 & PCOLCE & $"$ \\
\hline & Latent-transforming growth & & \\
\hline & factor beta-binding protein 2 & LTBP2 & $"$ \\
\hline & Collagen alpha-1(VI) chain & COL6A1 & $"$ \\
\hline & Decorin (Fragment) & DCN & $"$ \\
\hline & Chitinase-3-like protein 1 & CHI3L1 & $"$ \\
\hline & Microfibril-associated glycoprotein 4 & MFAP4 & " \\
\hline & Cartilage intermediate layer protein 1 & CILP & $"$ \\
\hline & Collagen alpha-1(I) chain & COL1A1 & $"$ \\
\hline & Myocilin & MYOC & Motor activity \\
\hline & Isoform 2 of Gelsolin & GSN & Structural constituent of cytoskeleton \\
\hline & Afamin & AFM & Structural molecule activity \\
\hline & Protein metabolism & & \\
\hline & Serum amyloid P-component & APCS & Binding \\
\hline & Carboxypeptidase M & CPM & Carboxypeptidase activity \\
\hline & Mast cell carboxypeptidase A & CPA3 & $"$ \\
\hline & $78 \mathrm{kDa}$ glucose-regulated protein & HSPA5 & Chaperone activity \\
\hline & Calreticulin (Fragment) & CALR & $"$ \\
\hline & Protein disulfide-isomerase A6 & PDIA6 & Isomerase activity \\
\hline & Matrix metalloproteinase-9 & MMP9 & Metallopeptidase activity \\
\hline & Neutrophil collagenase & MMP8 & $"$ \\
\hline & Plasminogen & PLG & Peptidase activity \\
\hline & Thrombin light chain & $\mathrm{F} 2$ & Peptidase activity \\
\hline & Isoform 2 of Inter-alpha-trypsin inhibitor heavy chain H5 & ITIH5 & Protease inhibitor activity \\
\hline & Isoform 4 of Inter-alpha-trypsin inhibitor heavy chain $\mathrm{H} 4$ & ITIH4 & $"$ \\
\hline & Inter-alpha-trypsin inhibitor heavy chain $\mathrm{H} 2$ & ITIH2 & $"$ \\
\hline & Plasma protease $\mathrm{C} 1$ inhibitor & SERPING1 & " \\
\hline & Isoform 2 of Alpha-2-antiplasmin & SERPINF2 & " \\
\hline & Heparin cofactor 2 & SERPIND1 & $"$ \\
\hline & Kallistatin & SERPINA4 & $"$ \\
\hline & von Willebrand factor & VWF & Protein binding \\
\hline & Isoform 2 of Tryptase alpha/beta-1 & TPSAB 1 & Serine-type peptidase activity \\
\hline & CMA1 protein & CMA1 & $"$ \\
\hline & Neutrophil elastase & ELANE & $"$ \\
\hline & Immune response & & \\
\hline & Zinc-alpha-2-glycoprotein & AZGP1 & Cell adhesion molecule activity \\
\hline & Platelet factor 4 & PF4 & Chemokine activity \\
\hline
\end{tabular}


Table VIII. Continued

\begin{tabular}{|c|c|c|c|}
\hline $\mathrm{CM}$ & Biological process & GN & Molecular function \\
\hline & Growth-regulated alpha protein & CXCL1 & $"$ \\
\hline & $\mathrm{C}-\mathrm{X}-\mathrm{C}$ motif chemokine 2 & CXCL2 & $"$ \\
\hline & Complement $\mathrm{C} 3$ & $\mathrm{C} 3$ & Complement activity \\
\hline & Complement factor $\mathrm{H}$-related protein 1 & CFHR1 & " \\
\hline & Complement component $\mathrm{C} 9$ & C9 & $"$ \\
\hline & Complement factor $\mathrm{D}$ & CFD & $"$ \\
\hline & Complement $\mathrm{C} 1 \mathrm{q}$ subcomponent subunit $\mathrm{C}$ & C1QC & $"$ \\
\hline & Complement $\mathrm{C} 1 \mathrm{~s}$ subcomponent (Fragment) & $\mathrm{C} 1 \mathrm{~S}$ & $"$ \\
\hline & Complement C5 & $\mathrm{C} 5$ & $"$ \\
\hline & Clusterin beta chain (Fragment) & CLU & $"$ \\
\hline & Complement decay-accelerating factor & CD55 & $"$ \\
\hline & Complement factor $\mathrm{H}$ & $\mathrm{CFH}$ & Complement binding \\
\hline & Azurocidin & AZU1 & Defense/immunity protein activity \\
\hline & Galectin-3-binding protein & LGALS3BP & ECM structural constituent \\
\hline & Serglycin & SRGN & " \\
\hline & Beta-2-microglobulin & $\mathrm{B} 2 \mathrm{M}$ & MHC class I receptor activity \\
\hline & Isoform 3 of CD109 antigen & CD109 & Molecular function unknown \\
\hline & Cell communication; Signal transduction & & \\
\hline & Cell surface glycoprotein MUC18 & MCAM & Cell adhesion molecule activity \\
\hline & Periostin & POSTN & " \\
\hline & $\begin{array}{l}\text { Isoform Delta14-15 of Platelet } \\
\text { endothelial cell adhesion molecule }\end{array}$ & PECAM1 & $"$ \\
\hline & Dystroglycan & DAG1 & $"$ \\
\hline & Isoform 6 of Tenascin & $\mathrm{TNC}$ & $"$ \\
\hline & G-protein coupled receptor 124 & GPR124 & G-protein coupled receptor activity \\
\hline & Peptidyl-prolyl cis-trans isomerase FKBP2 & FKBP2 & Isomerase activity \\
\hline & $\mathrm{ADM} 2$ & ADM2 & Peptide hormone \\
\hline & Chondroitin sulfate proteoglycan 4 & CSPG4 & Protein binding \\
\hline & Scavenger receptor cysteine-rich type 1 protein M130 & CD163 & Receptor activity \\
\hline & Prolow-density lipoprotein receptor-related protein 1 & LRP1 & " \\
\hline & Signal-regulatory protein beta- 1 isoform 3 & SIRPB1 & $"$ \\
\hline & Bone morphogenetic protein 3 & BMP3 & $"$ \\
\hline & Isoform 3 of Receptor-type tyrosine-protein phosphatase $S$ & PTPRS & Receptor signaling protein tyr phosphatase activity \\
\hline & Receptor-type tyrosine-protein phosphatase $\mathrm{T}$ & PTPRT & " \\
\hline & Transport & & \\
\hline & Isoform 4 of Chloride channel CLIC-like protein 1 & CLCC1 & Ion channel activity \\
\hline & Isoform DeltaLf of Lactotransferrin & LTF & Transporter activity \\
\hline & Transthyretin & TTR & $"$ \\
\hline & Vitamin D-binding protein & GC & $"$ \\
\hline & Neutrophil gelatinase-associated lipocalin & $\mathrm{LCN} 2$ & $"$ \\
\hline & Apolipoprotein E (Fragment) & APOE & $"$ \\
\hline & Apolipoprotein C-III & APOC3 & $"$ \\
\hline & Apolipoprotein D (Fragment) & APOD & $"$ \\
\hline & Apolipoprotein B-100 & APOB & $"$ \\
\hline & Adaptive immunity, Immunity & & \\
\hline & Ig lambda chain V-IV region Hil & IGLV3-25 & $\begin{array}{l}\text { Antigen binding/serine-type } \\
\text { endopeptidase activity }\end{array}$ \\
\hline & Ig kappa chain V-I region Wes & IGKV1D-12 & " \\
\hline & Ig heavy chain V-III region VH26 & IGHV3-23 & $"$ \\
\hline & Ig heavy chain V-III region BUT & IGHV3-53 & $"$ \\
\hline & Ig kappa chain V-I region HK102 (Fragment) & IGKV1-5 & $"$ \\
\hline & Ig heavy chain V-I region V35 & IGHV1-2 & $"$ \\
\hline & Ig heavy chain V-III region JON & IGHV3-7 & $"$ \\
\hline & Metabolism; Energy pathways & & \\
\hline & Liver carboxylesterase 1 & CES1 & Hydrolase activity \\
\hline & Isoform 2 of Arylsulfatase A & ARSA & Catalytic activity \\
\hline & Epoxide hydrolase 1 & EPHX1 & Hydrolase activity \\
\hline & Lysozyme C & LYZ & $"$ \\
\hline
\end{tabular}


Table VIII. Continued

\begin{tabular}{|c|c|c|c|}
\hline $\mathrm{CM}$ & Biological process & GN & Molecular function \\
\hline & Ceruloplasmin & $\mathrm{CP}$ & Oxidoreductase activity \\
\hline & Isoform H14 of Myeloperoxidase & MPO & " \\
\hline & Glutathione peroxidase 3 & GPX3 & Peroxidase activity \\
\hline & Isoform 2 of Glucosidase 2 subunit beta & PRKCSH & Glucosidase activity \\
\hline & Apoptosis & & \\
\hline & Histidine-rich glycoprotein & HRG & Binding \\
\hline & Peroxidasin homolog (Fragment) & PXDN & Peroxidase activity \\
\hline & Organogenesis; Cell communication; Signal transduction & & \\
\hline & Mimecan & OGN & Growth factor activity \\
\hline & $\begin{array}{l}\text { Regulation of nucleobase, nucleoside, } \\
\text { nucleotide and nucleic acid metabolism }\end{array}$ & & \\
\hline & Non-secretory ribonuclease & RNASE2 & Ribonuclease activity \\
\hline & Signal transduction; Cell migration; Morphogenesis; & & \\
\hline & Immune response & & \\
\hline & Neuropilin-1 & NRP1 & Receptor activity \\
\hline & L-arabinose metabolic process & & \\
\hline & Otogelin-like protein & OTOGL & Alpha-L-arabinofuranosidase activity \\
\hline & Biological_process unknown & & \\
\hline & Isoform 2 of Target of Nesh-SH3 & ABI3BP & Molecular function unknown \\
\hline & Isoform 2 of $\mathrm{NAD}(\mathrm{P}) \mathrm{H}$-hydrate epimerase & APOA1BP & " \\
\hline & LOC644656 protein (Fragment) & LOC644656 & \\
\hline \multirow[t]{7}{*}{$\mathrm{T} 2$} & Adaptive immunity, Immunity & & \\
\hline & Ig heavy chain V-III region KOL & IGHV3-33 & $\begin{array}{l}\text { Antigen binding/serine-type } \\
\text { endopeptidase activity }\end{array}$ \\
\hline & Ig heavy chain V-II region ARH-77 & IGHV4-34 & $n$ \\
\hline & Protein metabolism & & \\
\hline & Coagulation factor XII & $\mathrm{F} 12$ & Peptidase activity \\
\hline & Cell communication; Signal transduction & & \\
\hline & Alpha-2-HS-glycoprotein & AHSG & Defense/immunity protein activity \\
\hline \multirow[t]{24}{*}{$\mathrm{T} 3$ and $\mathrm{T} 2$} & Immune response & & \\
\hline & Isoform 2 of Complement C4-A & $\mathrm{C} 4 \mathrm{~A}$ & Complement activity \\
\hline & Alpha-1-acid glycoprotein 1 & ORM1 & Defense/immunity protein activity \\
\hline & Alpha-1-acid glycoprotein 2 & ORM2 & " \\
\hline & Pentraxin-related protein PTX3 & PTX3 & $"$ \\
\hline & Biological_process unknown & & \\
\hline & Olfactomedin-like protein 1 & OLFML1 & Molecular function unknown \\
\hline & Leucine-rich alpha-2-glycoprotein & LRG1 & " \\
\hline & Endosialin & $\mathrm{CD} 248$ & Receptor activity \\
\hline & Protein metabolism & & \\
\hline & Antithrombin-III & SERPINC1 & Protease inhibitor activity \\
\hline & Lysyl-bradykinin & KNG1 & $"$ \\
\hline & Isoform Gamma-A of Fibrinogen gamma chain & FGG & Protein binding \\
\hline & Cell communication; Signal transduction & & \\
\hline & Basal cell adhesion molecule (Fragment) & BCAM & Cell adhesion molecule activity \\
\hline & Cell growth and/or maintenance & & \\
\hline & Tenascin-X OS=Homo sapiens & TNXB & ECM structural constituent \\
\hline & Laminin subunit beta-2 & LAMB2 & " \\
\hline & Adaptive immunity, Immunity & & \\
\hline & Ig lambda chain V-III region LOI & IGLV3-21 & $\begin{array}{l}\text { Antigen binding/serine-type } \\
\text { endopeptidase activity }\end{array}$ \\
\hline & Metabolism; Energy pathways & & \\
\hline & Extracellular superoxide dismutase $[\mathrm{Cu}-\mathrm{Zn}]$ & SOD3 & Superoxide dismutase activity \\
\hline & Transport & & \\
\hline & Beta-2-glycoprotein 1 & $\mathrm{APOH}$ & Transporter activity \\
\hline \multirow[t]{4}{*}{$\mathrm{T} 3$ and $\mathrm{BPH}$} & Protein metabolism & & \\
\hline & Isoform 2 of Plasminogen activator inhibitor 1 & SERPINE1 & Protease inhibitor activity \\
\hline & Fibrinogen beta chain & FGB & Protein binding \\
\hline & Isoform 2 of Fibrinogen alpha chain & FGA & $"$ \\
\hline
\end{tabular}


Table VIII. Continued

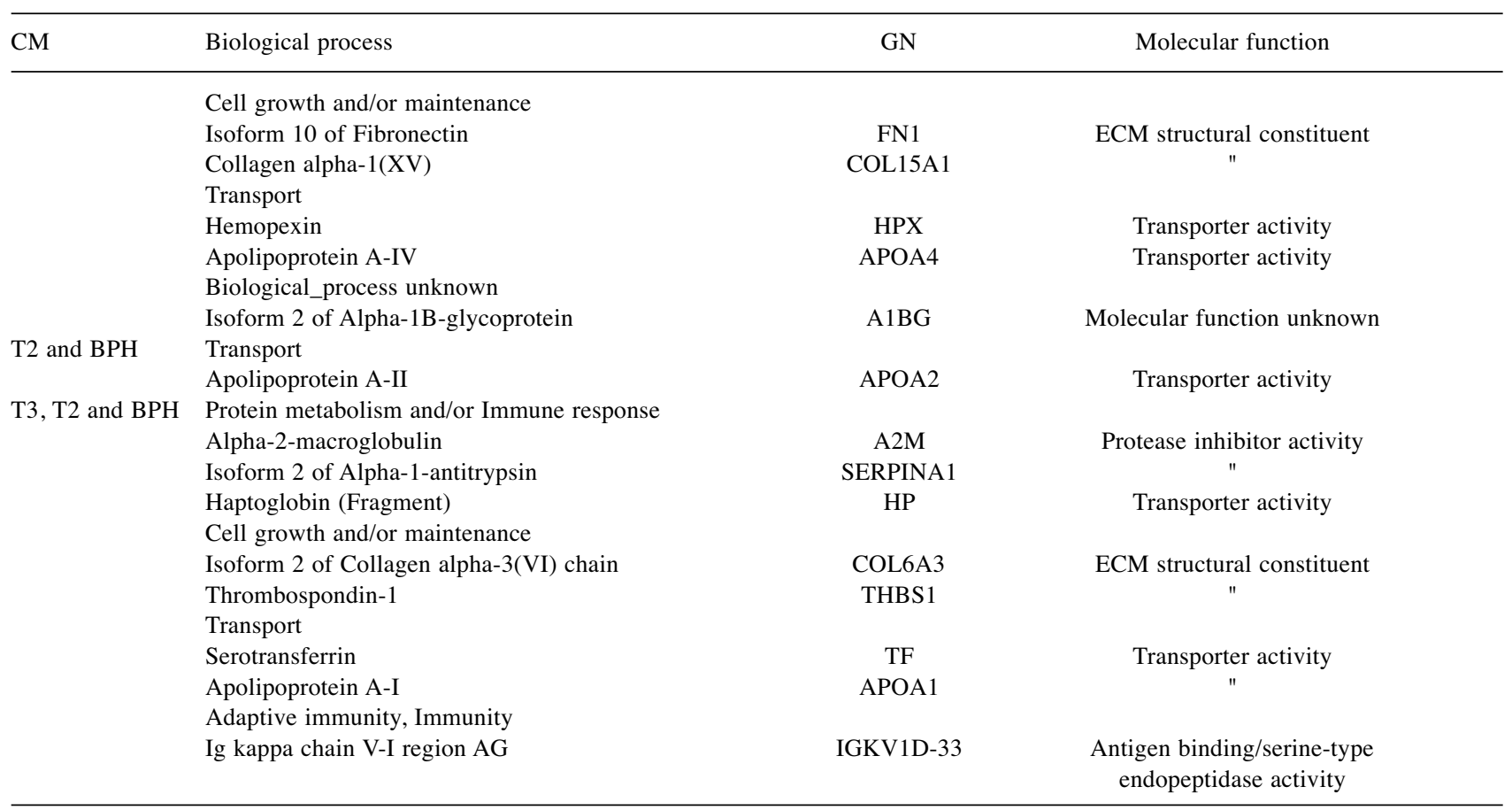

in CM-T3 (3.2\%) (Figure 5D). Allot et al. (80) showed that the highest degree of differential genetic regulation of a poorly differentiated esophageal adenocarcinoma, appeared when the cell line was co-cultured with whole visceral adipose tissue, speculating that the cells of the stromal vascular fraction (source rich in preadipocytes) are the main effectors of these genetic alterations, since under coculture with adipocytes the effect decreased. This could relate to the results of this study because a higher percentage of preadipocyte relative to adipocyte genes were detected in more advanced disease. It can be hypothesized that 1) the lower percentage of preadipocyte proteins in CMs-T could be due to a diminished number of these cells since they could have migrated towards the tumour; 2) adipocytes from fat of tumour samples could have dedifferentiated into preadipocytes and reprogrammed into CAA. However, a minor percentage of adipocyte proteins could suggest some accidental adipose tissue damage both during isolation and over time under culture conditions; 3) this comparison should consider which molecules are expressed by adipocytes and preadipocytes from healthy individuals, when it is already known that tumour cells can induce different cells within adipose tissue to secrete a particular pattern of molecules $(6,16,17,81)$. On the other hand, a comparison of the proteins from our CMs showed that more than $50 \%$ were expressed in both prostate gland and PCa (Figure 5D).
Classification of secreted proteins. CMs proteins were analyzed for the possibility of secretion using ProteINSIDE database and further subjected to bioinformatics analysis. This omic tool identifies proteins secreted through the classical pathway (endoplasmic reticulum/Golgi apparatus dependent pathway) by the SignalP tool as well as proteins secreted by non-classical pathway or ER/Golgi-independent pathways. ProteINSIDE checks the subcellular location of proteins and compares their annotation relatively to the list of GO terms related to secretion. Lastly, to support these predictions (classical and non-classical pathways) ProteINSIDE runs the TargetP software that predicts the subcellular location of the proteins using the amino acid sequence. The double query of protein secretion, both by the signal peptide prediction and the GO annotation, is unique to ProteINSIDE. The number of predicted CMs proteins secreted by classical and non-classical pathways is shown in Table VII. CM-T2 and CM-BPH had the higher percentage of secreted proteins (74 and 79\%, respectively) relative to CM-T3 $(58 \%)$ by both classical and non-classical pathways. This could be related to the fact that $\mathrm{CM}-\mathrm{T} 3$ proteins showed a more uniform distribution in different cellular compartments (Figure 3D) unlike CM-BPH where more than $80 \%$ of their proteins were exosomal. Table VIII shows the list of proteins secreted by classical pathways for the three CMs and Table IX lists proteins potentially secreted by pathways that do not involve signal peptide (non-classical pathways). 
Table IX. List of proteins secreted by non-classical pathways according to ProteINSIDE tool.

\begin{tabular}{|c|c|c|c|}
\hline $\mathrm{CM}$ & Biological process & Gene name & Molecular function \\
\hline \multirow[t]{53}{*}{ T3 } & ATP biosynthetic process; Cannonical glycolysis & & \\
\hline & Pyruvate kinase isozymes M1/M2 & PKM & ADP and ATP binding \\
\hline & Biosynthetic process & & \\
\hline & $\begin{array}{l}\text { Isoform } 2 \text { of Adipocyte plasma membrane-associated protein } \\
\text { Cell communication; Signal transduction }\end{array}$ & APMAP & Arylestearasa activity \\
\hline & Isoform 4 of A-kinase anchor protein 9 & AKAP9 & Receptor signaling complex scaffold activity \\
\hline & EH domain-containing protein 1 & EHD1 & Calcium ion binding \\
\hline & Extended synaptotagmin-1 & ESYT1 & $"$ \\
\hline & Hippocalcin-like protein 1 & HPCAL1 & $"$ \\
\hline & Plastin-2 & LCP1 & $"$ \\
\hline & Myosin regulatory light chain $12 \mathrm{~A}$ & MYL12A & $"$ \\
\hline & Phosphatidylethanolamine-binding protein 1 & PEBP1 & Protease inhibitor activity \\
\hline & $\begin{array}{l}\text { cAMP-dependent protein kinase catalytic } \\
\text { subunit beta (Fragment) }\end{array}$ & PRKACB & Protein serine/threonine kinase activity \\
\hline & $\begin{array}{l}\text { Isoform } 2 \text { of Receptor-type tyrosine-protein } \\
\text { phosphatase gamma }\end{array}$ & PTPRG & $\begin{array}{l}\text { Receptor signaling protein } \\
\text { tyrosine phosphatase activity }\end{array}$ \\
\hline & Protein S100-A10 & S100A 10 & Calcium ion binding \\
\hline & Protein S100-A8 & S100A8 & " \\
\hline & $\begin{array}{l}\text { SH3 domain-binding glutamic acid-rich-like protein } \\
\text { Cell differentiation }\end{array}$ & SH3BGRL & Unknown \\
\hline & Keratinocyte proline-rich protein & KPRP & Unknown \\
\hline & Adipogenesis regulatory factor & ADIRF & Cell differentiation \\
\hline & Cell growth and/or maintenance & & \\
\hline & Actin-related protein 3 & ACTR3 & Structural constitutent of cytoskeleton \\
\hline & Actin-related protein $2 / 3$ complex subunit 5 & ARPC5 & Cytoskeletal binding protein \\
\hline & Isoform 2 of Adenylyl cyclase-associated protein 1 & CAP1 & Unknown \\
\hline & F-actin-capping protein subunit alpha-2 & CAPZA2 & Structural constitutent of cytoskeleton \\
\hline & Isoform 2 of Clathrin heavy chain 1 & CLTC & Structural molecule activity \\
\hline & Isoform DPII of Desmoplakin & DSP & Structural constitutent of cytoskeleton \\
\hline & Isoform 5 of Filamin-B & FLNB & Cytoskeletal binding protein \\
\hline & Isoform 2 of Kinectin & KTN1 & Cytoskeletal anchoring activity \\
\hline & Isoform 6 of Microtubule-associated protein 4 & MAP4 & Cytoskeletal protein binding \\
\hline & Myosin-10 & MYH10 & Structural molecule activity \\
\hline & Isoform 4 of Myosin-11 & MYH11 & $"$ \\
\hline & Myosin-9 & MYH9 & $"$ \\
\hline & Isoform 2 of Unconventional myosin-Ic & MYO1C & Motor activity \\
\hline & Unconventional myosin-Ie & MYO1E & $"$ \\
\hline & Profilin-1 & PFN1 & Cytoskeletal binding protein \\
\hline & Isoform 3 of Spectrin beta chain, erythrocytic & SPTB & Structural molecule activity \\
\hline & Utrophin & UTRN & Cytoskeletal anchoring activity \\
\hline & Cholesterol metabolic process & & \\
\hline & Erlin-1 & ERLIN1 & Cholesterol binding \\
\hline & Cytoskeleton organization and biogenesis & & \\
\hline & Ras GTPase-activating-like protein IQGAP1 & IQGAP1 & GTPase activator activity \\
\hline & Vasodilator-stimulated phosphoprotein & VASP & Cytoskeletal protein binding \\
\hline & Fatty acid beta-oxidtion & & \\
\hline & Isoform 2 of Enoyl-CoA delta isomerase 1, mitochondrial & ECI1 & Isomerase and hydratas activity \\
\hline & $\begin{array}{l}\text { Delta(3,5)-Delta(2,4)-dienoyl-CoA isomerase, mitochondrial } \\
\text { Immune response }\end{array}$ & $\mathrm{ECH} 1$ & Isomerase activity \\
\hline & Membrane primary amine oxidase & AOC3 & Cell adhesion molecule activity \\
\hline & C4b-binding protein alpha chain & C4BPA & Complement activity \\
\hline & D-dopachrome decarboxylase & DDT & Isomerase activity \\
\hline & Ig gamma-1 chain $\mathrm{C}$ region & IGHG1 & Antigen binding \\
\hline & Ig gamma- 2 chain $\mathrm{C}$ region & IGHG2 & " \\
\hline & Ig gamma- 4 chain $\mathrm{C}$ region & IGHG4 & $"$ \\
\hline & Ig heavy chain V-I region V35 & IGHV1-2 & $"$ \\
\hline & Ig heavy chain V-III region JON & IGHV3-7 & $"$ \\
\hline & Immunoglobulin lambda-like polypeptide 5 & IGLL5 & $"$ \\
\hline
\end{tabular}




\begin{tabular}{|c|c|c|c|}
\hline \multirow[t]{2}{*}{$\mathrm{CM}$} & Biological process & Gene name & Molecular function \\
\hline & \multicolumn{3}{|l|}{ Metabolism } \\
\hline & Platelet glycoprotein 4 & CD36 & Receptor activity \\
\hline & \multicolumn{3}{|l|}{ Metabolism; Energy pathways } \\
\hline & Adenosylhomocysteinase & $\mathrm{AHCY}$ & Hydrolase activity \\
\hline & $\begin{array}{l}\text { Isoform } 2 \text { of Cytosolic 10-formyltetrahydrofolate } \\
\text { dehydrogenase }\end{array}$ & ALDH1L1 & Catalytic activity \\
\hline & Flavin reductase $(\mathrm{NADPH})$ & BLVRB & Oxidoreductase activity \\
\hline & Carbonic anhydrase 1 & CA1 & Catalytic activity \\
\hline & Carbonic anhydrase 2 & CA2 & " \\
\hline & Catalase & CAT & Oxidoreductase activity \\
\hline & Acyl-CoA-binding protein & DBI & Receptor binding \\
\hline & Alpha-enolase & ENO1 & Catalytic activity \\
\hline & Coagulation factor XIII A chain & F13A1 & Transferase activity \\
\hline & Fumarylacetoacetase & FAH & Hydrolase activity \\
\hline & Polypeptide $\mathrm{N}$-acetylgalactosaminyltransferase 5 & GALNT5 & Galacotsyltransferase activity \\
\hline & Isoform 2 of Lactoylglutathione lyase & GLO1 & Lyase activity \\
\hline & Glutaredoxin-1 & GLRX & Oxidoreductase activity \\
\hline & Aspartate aminotransferase & GOT1 & Transaminase activity \\
\hline & \multicolumn{3}{|l|}{ dehydrogenase $[\mathrm{NAD}(+)]$, cytoplasmic } \\
\hline & Glutathione S-transferase $\mathrm{P}$ & GSTP1 & Gluthatione transferase activity \\
\hline & Hypoxanthine-guanine phosphoribosyltransferase & HPRT1 & Catalytic activity \\
\hline & Isocitrate dehydrogenase [NADP] cytoplasmic & IDH1 & " \\
\hline & Isoform 4 of L-lactate dehydrogenase $\mathrm{A}$ chain & LDHA & $"$ \\
\hline & L-lactate dehydrogenase B chain & LDHB & $"$ \\
\hline & Malate dehydrogenase, cytoplasmic & MDH1 & $"$ \\
\hline & Vesicle-fusing ATPase & NSF & ATPase activity \\
\hline & Phosphoglycerate mutase 1 & PGAM1 & Catalytic activity \\
\hline & 6-phosphogluconate dehydrogenase, decarboxylating & PGD & " \\
\hline & Phosphoglycerate kinase 1 & PGK1 & $"$ \\
\hline & Purine nucleoside phosphorylase (Fragment) & PNP & Phosphorylase activity \\
\hline & Peroxiredoxin-2 & PRDX2 & Peroxidase activity \\
\hline & Thioredoxin-dependent peroxide reductase, mitochondrial & PRDX3 & " \\
\hline & \multicolumn{3}{|l|}{$\begin{array}{l}\text { Isoform Cytoplasmic+peroxisomal of } \\
\text { Peroxiredoxin-5, mitochondrial }\end{array}$} \\
\hline & Peroxiredoxin-6 & PRDX6 & Peroxidase activity \\
\hline & Isoform 2 of Glycogen phosphorylase, liver form & PYGL & Phosphorylase activity \\
\hline & Dihydropteridine reductase & QDPR & Catalytic activity \\
\hline & Superoxide dismutase $[\mathrm{Cu}-\mathrm{Zn}]$ & SOD1 & Superoxide dismutase activity \\
\hline & Threonine--tRNA ligase, cytoplasmic & TARS & Ligase activity \\
\hline & Thioredoxin & $\mathrm{TXN}$ & Catalytic activity \\
\hline & Isoform 2 of UDP-glucose:glycoprotein glucosyltransferase 1 & UGGT1 & Transferase activity \\
\hline & Isoform 2 of UTP--glucose-1-phosphate uridylyltransferase & UGP2 & Nucleotidyltransferase activity \\
\hline & Transitional endoplasmic reticulum ATPase & $\mathrm{VCP}$ & ATPase activity \\
\hline & \multicolumn{3}{|l|}{ Protein folding; peptide metabolism } \\
\hline & Peptidyl-prolyl cis-trans isomerase A & PPIA & Isomerase activity \\
\hline & \multicolumn{3}{|l|}{ Protein metabolism } \\
\hline & Calpain-1 catalytic subunit & CAPN1 & Cystein-peptidase activity \\
\hline & T-complex protein 1 subunit theta & ССТ8 & Chaperone activity \\
\hline & Cystatin-B & CSTB & Protease inhibitor activity \\
\hline & DnaJ homolog subfamily A member 1 & DNAJA1 & Heat shock protein activity \\
\hline & Heat shock $70 \mathrm{kDa}$ protein $1 \mathrm{~A} / 1 \mathrm{~B}$ & HSPA1A & Chaperone activity \\
\hline & Heat shock $70 \mathrm{kDa}$ protein 4 & HSPA4 & " \\
\hline & Heat shock protein beta- 1 & HSPB 1 & $"$ \\
\hline & Isoform 3 of Leukotriene A-4 hydrolase & LTA4H & Hydrolase activity \\
\hline & Puromycin-sensitive aminopeptidase & NPEPPS & Aminopeptidase activity \\
\hline & Peptidyl-prolyl cis-trans isomerase B & PPIB & Chaperone activity \\
\hline & Proteasome subunit alpha type-5 & PSMA5 & Ubiquitin-specific protease activity \\
\hline
\end{tabular}




\begin{tabular}{|c|c|c|c|}
\hline $\mathrm{CM}$ & Biological process & Gene name & Molecular function \\
\hline & $\begin{array}{l}\text { Proteasome (Prosome, macropain) subunit, } \\
\text { alpha type, } 6 \text {, isoform CRA_a }\end{array}$ & PSMA6 & $"$ \\
\hline & Proteasome subunit alpha type-7 & PSMA7 & $"$ \\
\hline & Proteasome subunit beta type-1 & PSMB1 & $"$ \\
\hline & $60 \mathrm{~S}$ acidic ribosomal protein $\mathrm{P} 1$ & RPLP1 & Structural constitutent of ribosome \\
\hline & 40 S ribosomal protein $\mathrm{S} 28$ & RPS28 & $"$ \\
\hline & Isoform 2 of Selenium-binding protein 1 & SELENBP1 & Unknown \\
\hline & Leukocyte elastase inhibitor & SERPINB1 & Protease inhibitor activity \\
\hline & Serpin B12 & SERPINB12 & $"$ \\
\hline & Serpin B6 & SERPINB6 & $"$ \\
\hline & Isoform 2 of Ubiquitin-conjugating enzyme E2 L3 & UBE2L3 & Ubiquitin-specific protease activity \\
\hline & Isoform 2 of Tryptophan--tRNA ligase, cytoplasmic & WARS & Ligase activity \\
\hline & Protein metabolism; Proteolysis and peptidolysis & & \\
\hline & Isoform 3 of Proteasome subunit beta type-5 & PSMB5 & Ubiquitin-specific protease activity \\
\hline & Protein metabolism; translation & & \\
\hline & Elongation factor 2 & EEF2 & Translation regulatory activity \\
\hline & Regulation of cell cycle & & \\
\hline & $14-3-3$ protein zeta/delta & YWHAZ & Receptor signaling complex scaffold activity \\
\hline & $\begin{array}{l}\text { Regulation of nucleobase, nucleoside, } \\
\text { nucleotide and nucleic acid metabolism }\end{array}$ & & \\
\hline & Cytoplasmic aconitate hydratase & $\mathrm{ACO} 1$ & Isomerase activity \\
\hline & Breast cancer type 2 susceptibility protein & BRCA2 & Transcription regulatory activity \\
\hline & DNA damage-binding protein 1 & DDB1 & DNA repair protein \\
\hline & Heterogeneous nuclear ribonucleoprotein A1 & HNRNPA1 & RNA binding \\
\hline & Nucleolin & NCL & RNA binding \\
\hline & Signal transduction; Vesicle-mediated transport & & \\
\hline & Intersectin 1 long form variant 4 & ITSN1 & Receptor signaling complex scaffold activity \\
\hline & Synaptic vesicle transport & & \\
\hline & Isoform 2 of Protein piccolo & PCLO & Structural constitutent of cytoskeleton \\
\hline & Transport & & \\
\hline & Early endosome antigen 1 & EEA1 & Auxiliary transport protein activity \\
\hline & Ferritin light chain & FTL & Storage protein \\
\hline & $\mathrm{BTB} / \mathrm{POZ}$ domain-containing protein KCTD12 & KCTD12 & Ion channel activity \\
\hline & Ribosome-binding protein 1 & RRBP1 & Transmembrane receptor activity \\
\hline & Non-specific lipid-transfer protein & $\mathrm{SCP} 2$ & Auxiliary transport protein activity \\
\hline & $\begin{array}{l}\text { Solute carrier family } 2 \text {, facilitated glucose } \\
\text { transporter member } 1 \text { (Fragment) }\end{array}$ & SLC2A 1 & " \\
\hline & Band 3 anion transport protein & SLC4A1 & $"$ \\
\hline & Isoform 2 of Syntaxin-7 & STX7 & Binding protein \\
\hline & Synaptotagmin-like protein 5 & SYTL5 & Transporter activity \\
\hline & General vesicular transport factor p115 (Fragment) & USO1 & Transporter activity \\
\hline & Unknown & & \\
\hline & Barrier-to-autointegration factor & BANF1 & DNA binding \\
\hline & Dynein light chain roadblock-type 2 & DYNLRB2 & Unknown \\
\hline & SH3 domain-binding glutamic acid-rich-like protein 2 & SH3BGRL2 & " \\
\hline \multirow[t]{2}{*}{$\mathrm{T} 2$} & $\begin{array}{l}\text { Regulation of nucleobase, nucleoside, } \\
\text { nucleotide and nucleic acid metabolism }\end{array}$ & & \\
\hline & $\begin{array}{l}\text { Isoform } \mathrm{A} 2 \text { of Heterogeneous nuclear } \\
\text { ribonucleoproteins } \mathrm{A} 2 / \mathrm{B} 1\end{array}$ & HNRNPA2B1 & Transcription factor binding \\
\hline \multirow[t]{9}{*}{$\mathrm{T} 2$ and $\mathrm{T} 3$} & Aldheyde metabolism & & \\
\hline & Retinal dehydrogenase 1 & ALDH1A1 & Aldheyde dehydrogenase activity \\
\hline & Cell communication; Signal transduction & & \\
\hline & 14-3-3 protein gamma & YWHAG & Receptor signaling complex scaffold activity \\
\hline & Cell growth and/or maintenance & & \\
\hline & Actin, cytoplasmic 1 & АCTB & Structural constitutent of cytoskeleton \\
\hline & Desmin & DES & " \\
\hline & Spectrin alpha chain, non-erythrocytic 1 & SPTAN1 & $"$ \\
\hline & Spectrin beta chain, non-erythrocytic 1 & SPTBN1 & $"$ \\
\hline
\end{tabular}


Table IX. Continued

\begin{tabular}{|c|c|c|c|}
\hline $\mathrm{CM}$ & Biological process & Gene name & Molecular function \\
\hline & Talin-1 & TLN1 & Cytoskeletal protein binding \\
\hline & Isoform 1 of Vinculin & VCL & " \\
\hline & Immune response & & \\
\hline & Ig alpha-1 chain $\mathrm{C}$ region & IGHA1 & Antigen binding \\
\hline & Ig alpha- 2 chain $\mathrm{C}$ region & IGHA2 & " \\
\hline & Ig mu heavy chain disease protein & IGHM & $"$ \\
\hline & Metabolism; Energy pathways & & \\
\hline & Aldo-keto reductase family 1 member $\mathrm{C} 3$ & AKR1C3 & Catalytic activity \\
\hline & Aldehyde dehydrogenase, mitochondrial & ALDH2 & " \\
\hline & Isoform 2 of Triosephosphate isomerase & TPI1 & Isomerase activity \\
\hline & Protein metabolism & & \\
\hline & Proteasome subunit alpha type- 1 & PSMA1 & Peptidase activity \\
\hline & Proteasome subunit beta type- 4 & PSMB4 & Ubiquitin-specific protease activity \\
\hline & Transport & & \\
\hline & B-cell receptor-associated protein 31 & BCAP31 & Transporter activity \\
\hline & Hemoglobin subunit delta & HBD & " \\
\hline & Unknown & & \\
\hline & Hornerin & HRNR & Unknown \\
\hline \multirow{23}{*}{$\mathrm{T} 3$ y BPH } & Cell adhesion; Signal transduction & & \\
\hline & Ras suppressor protein 1 & RSU1 & Unknown \\
\hline & Junction plakoglobin & JUP & Cell adhesion molecule activity \\
\hline & Protein S100-A9 & S100A9 & Calcium ion binding \\
\hline & Cell growth and/or maintenance & & \\
\hline & Isoform 2 of Alpha-actinin-1 & ACTN1 & Cytoskeletal protein binding \\
\hline & Alpha-actinin-4 & ACTN4 & Structural constitutent of cytoskeleton \\
\hline & Tubulin alpha-1A chain & TUBA1A & " \\
\hline & Immune response & & \\
\hline & Ig gamma- 3 chain $\mathrm{C}$ region & IGHG3 & Antigen binding \\
\hline & Ig kappa chain $\mathrm{C}$ region & IGKC & $"$ \\
\hline & Ig lambda- 2 chain $\mathrm{C}$ regions & IGLC2 & $"$ \\
\hline & Metabolism; Energy pathways & & \\
\hline & Phosphoglucomutase-1 & PGM1 & Catalytic activity \\
\hline & Peroxiredoxin-1 & PRDX1 & Peroxidase activity \\
\hline & Muscle contraction & & \\
\hline & Neuroblast differentiation-associated protein AHNAK & AHNAK & Protein binding \\
\hline & Protein metabolism & & \\
\hline & $10 \mathrm{kDa}$ heat shock protein, mitochondrial & HSPE1 & Heat shock protein activity \\
\hline & $\begin{array}{l}\text { Regulation of nucleobase, nucleoside, } \\
\text { nucleotide and nucleic acid metabolism }\end{array}$ & & \\
\hline & Ribonuclease inhibitor & RNH1 & Translation regulatory activity \\
\hline & Unknown & & \\
\hline & Transgelin-2 & TAGLN2 & Unknown \\
\hline \multirow[t]{14}{*}{$\mathrm{T} 3, \mathrm{~T} 2$ and $\mathrm{BPH}$} & Cell communication; Signal transduction & & \\
\hline & Fatty acid-binding protein, adipocyte & FABP4 & Chaperone activity \\
\hline & Cell growth and/or maintenance & & \\
\hline & Isoform 2 of Collagen alpha- 1 (XIV) chain & COL14A1 & Extracellular matrix structural constitutent \\
\hline & Isoform 2 of Filamin-A & FLNA & Cytoskeletal anchoring activity \\
\hline & Isoform 2 of Tropomyosin alpha- 4 chain & TPM4 & Structural constitutent of cytoskeleton \\
\hline & Vimentin & VIM & " \\
\hline & Immune response & & \\
\hline & Galectin-1 & LGALS1 & Receptor binding \\
\hline & Metabolism; Energy pathways & & \\
\hline & $\begin{array}{l}\mathrm{N}(\mathrm{G}), \mathrm{N}(\mathrm{G}) \text {-dimethylarginine dimethylaminohydrolase } \\
2 \text { (Fragment) }\end{array}$ & DDAH2 & Hydrolase activity \\
\hline & Glucose-6-phosphate isomerase & GPI & Isomerase activity \\
\hline & $\begin{array}{l}\text { Regulation of nucleobase, nucleoside, } \\
\text { nucleotide and nucleic acid metabolism }\end{array}$ & & \\
\hline & Histone $\mathrm{H} 4$ & HIST1H4A & DNA binding \\
\hline
\end{tabular}


Table X. Comparison of secretomes from previous literature.

\begin{tabular}{|c|c|c|c|c|c|}
\hline $\begin{array}{l}\text { Previous proteomic } \\
\text { literature (\# reference) }\end{array}$ & $\begin{array}{l}\text { Human adipose } \\
\text { source }\end{array}$ & BMI & $\begin{array}{l}\text { \# Proteins } \\
\text { Literature }\end{array}$ & $\begin{array}{l}\text { \# Overlap proteins } \\
\text { CMs- } \mathrm{T}(\mathrm{n}=573)\end{array}$ & $\begin{array}{l}\text { \# Overlap proteins } \\
\text { CM-BPH }(n=52)\end{array}$ \\
\hline Lapeire L. et al. (17) & Breast associated/breast cancer & no data & 668 & $274(48 \%)$ & $45(87 \%)$ \\
\hline Alvarez-Llamas et al. (18) & Visceral non-carcinogenic gynecological & $19-31$ & 259 & $139(24 \%)$ & $22(42 \%)$ \\
\hline Lher S. et al. (85) & Subcutaneous/adipocyte/healthy female & $26.2 \pm 0.6$ & 347 & $164(29 \%)$ & $24(46 \%)$ \\
\hline Zhong et al. (65) & Subcutaneous/adipocyte/healthy female & $36 \pm 7.6$ & 420 & $178(31 \%)$ & $26(50 \%)$ \\
\hline Zvonic et al. (86) & Subcutaneous/ASC/female & $25.7 \pm 3.8$ & 101 & $41(7 \%)$ & $6(12 \%)$ \\
\hline Delany et al. (87) & Subcutaneous/ASC/healthy male \& female & $30.4 \pm 7.1$ & 172 & $68(12 \%)$ & $6(12 \%)$ \\
\hline
\end{tabular}

BMI: Body mass index $\mathrm{kg} / \mathrm{m}^{2}$.

Comparison with previous literature. It was of interest to make a comparison of our results with previously available human adipose proteomic/secretome literature (Table $\mathrm{X}$ ). The comparison of our CMs-T (stages T2 and T3, n=573) with proteins detected in adipose tissue associated with breast cancer presented byLapeire et al. (17) revealed 274 superimposed proteins $(48 \%)$ while the comparison with CM-BPH $(n=52)$ revealed 48 proteins $(92 \%)$. Furthermore, comparison with proteins detected in visceral adipose tissue explants of noncarcinogenic gynecologic disorders, as described by AlvarezLlamas et al. (18), revealed 139 overlapped proteins with our CMs-T (24\%) and 22 overlapped proteins (42\%) with our CM$\mathrm{BPH}$ secretome. A comparison with proteins secreted by adipocytes from subcutaneous adipose tissue of women undergone elective plastic surgery (82) or panniculectomy surgery (65) showed $29-31 \%$ overlapping proteins with our CMs-T and $46 \%$ to $50 \%$ overlapping proteins with $\mathrm{CM}-\mathrm{BPH}$, respectively. A minor number of overlapping proteins was found when comparing adipose stem cells (ASC) from lipoaspirates of subcutaneous adipose tissue of male and/or female undergone plastic surgery $(83,84), 7 \%$ to $12 \%$ for CMs-T and $12 \%$ for CM-BPH. Thus, unlike CMs-T, a major percentage of proteins from $\mathrm{CM}-\mathrm{BPH}$ were common to adipose tissue depots. This result confirmed that PPAT secretome derived from patients with tumour have a unique secretion profile with many proteins not previously identified in adipose tissue. A simultaneous comparison with all the data sets described above, led us to create a list of specific proteins. Some of the detected proteins belonged to the serpin family. Among those, and not yet described in the context of adipocyte biology, SERPINA4, SERPINB12, SERPINB4, SERPIND1 were found. They are the largest and most broadly distributed superfamily of protease inhibitors; they have multiple functions including coagulation, host defence, and ischemia protection (85). Eight serpins were present in previously studied adipocyte proteomes and secretomes, the majority serving as extracellular protease inhibitors (84). In a cancer context, it was reported that circulating levels of kallistatin (SERPINA4) are markedly reduced in patients with PCa. Kallistatin's active site is essential for inhibiting tissue kallikrein's activity and modulating the synthesis of microRNAs, (miR-34a, miR-21 and miR-203) among other functions. Also, kallistatin's heparin-binding site is crucial for antagonizing the signalling pathways of vascular endothelial growth factor, tumour necrosis factor- $\alpha$, wnt, transforming growth factor- $\beta$ and epidermal growth factor (86). Another protein family detected in CM-T3 was SLC transporters (SLC2A1, SLC2A14, SLC4A1 and SLC9A3R). Recently, SLC transporters are receiving increasing attention in relation to cancer. Several transporters for essential nutrients are up-regulated in cancer and serve as tumour promoters (87). Several proteins related to regulation of complement activation (IGLV6-57, IGHV1-2, IGHV3-23, IGHV3-53, IGHV3-7, IGKV1-5, IGKV1D-12, IGLV3-25) were found. TGF-beta activated kinase 1 and MAP3K7 (MAP3K7/TAK1) binding protein 3 (TAB3, serine/threonine kinase) act as essential components of the MAP kinase signal transduction pathway and play an important role in the cascades of cellular responses to changes in the environment. Their inhibition decreases lipid accumulation in mesenchymal stem cells (MSCs), induced to differentiate into adipocytes and inhibit adipogenesis of 3T3-L1 preadipocytes (88). TAB3 was reported as an oncogene and a biomarker for ovarian cancer (89). All these results reinforce the idea that each adipose deposit has its own profile and is specific for disease and gender.

In a subsequent comparison with existing literature, related to $\mathrm{PCa}$ biomarkers candidates, several proteins were detected in our study. Among them: complement C5 (C5), complement factor B (CFB), complement component C9 (C9), ceruloplasmin $(\mathrm{CP})$, inter-alpha-trypsin inhibitor heavy chain H4 (ITIH4), alpha-1-antichymotrypsin (SERPINA3) and plasma protease $\mathrm{C} 1$ inhibitor (SERPING1) were detect in CMT3; antithrombin-II (SERPINC1) and leucine-rich alpha-2glycoprotein (LRG1) were detected in CMs-T. These proteins were found increased in progressing, relative to nonprogressing PCa (90). Furthermore, afamin (AFM), vitronectin (VTN) and lumican (LUM) was detected in CM-T3; beta-2glycoprotein 1 (APOH) was detected in CMs-T while alpha- 
2-HS-glycoprotein (AHSG) was detected only in CM-T2. Alpha-2-macroglobulin (A2M) was detected in the three CMs. Rheman et al. (90) found these last proteins increased in nonprogressing cancer relative to BPH in serum samples. Vitamin D-binding protein (GC), zinc-alpha-2-glycoprotein (AZGP1), elongation factor 1-alpha 1 (EEF1A1) and hemopexin (HPX) were detected in CM-T3 by us and were found increased in metastatic versus progressing cancer by the same authors. Glycoproteins associated to cancer could also be detected in CM-T3 secretome like periostin (POSTN), versican core protein (VCAN), fibrillin-1 (FBN1) and laminin subunit beta2 (LAMB2) which was also found in urine, while zinc-alpha2-glycoprotein (AZGP1) was found in urine and serum of aggressive PCa in a glycoproteomic work (91).

Relative protein quantification. The emPAI method for protein quantification was used since it provides an absolute abundance value that enables comparison of datasets. Relative emPAI (\%) were calculated for proteins. Applying this method, the abundance of shared proteins was compared and selected those with a two-fold change in emPAI (\%) between the proteins of the three CMs (Figure 5E), CM-T2 relative to CM-T3 proteins (Figure 5F) and CM-T3 relative to CM-BPH proteins (Figure 5G). Hemoglobin subunit alpha, a typical serum protein, appeared with high emPAI (\%) in all CMs (Figure 5E). Comparison of the three CMs indicated that fatty acid binding protein 4 was more abundant (19-fold) in CMT3 relative to CM-T2 and 4-fold relative to CM-BPH while histone $\mathrm{H} 4$ was more abundant (5-fold) in CM-T2 relative to CM-T3 and 8-fold to CM-BPH. Immunoglobulin kappa constant fraction was more abundant (2-fold) in CM-T3 relative to CM-T2. Antithrombin-III (SERPINC1), triosephosphate isomerase (TPI) and vinculin (VCL) were more abundant (3-fold) in CM-T3 relative to CM-T2. Alpha1-acid glycoprotein was more abundant (5-fold) in CM-T2 relative to $\mathrm{CM}-\mathrm{T} 3$.

SERPINC1, a protease with inhibitory activity, as well as angiogenesis and tumour growth inhibitor, was found increased in visceral adipose tissue of pre-obese diabetics relative to non-diabetic patients (92) and also found increased in healthy obese individuals (93). Its expression was increased in Gleason grade group 1 to 3, being higher in group 3 but was gradually lost in tumours with higher Gleason grade (94). The TPII gene was found up-regulated in the conditioned medium of BPH-1 and LNCaP cells (95) and down-regulated during differentiation of brown mouse preadipocytes (96). The rounding and aggregation of the 3T3 preadipocytes, while differentiating into adipocytes are accompanied with changes in cytoskeletal-extracellular matrix components, with changes in shape leading to a decrease in the positive vinculin focal adhesion (97). VCL, identified by quantitative proteomics, was highly expressed in PCa cells with high migration potential like PC3 cells (98).

\section{Discussion}

Proteins secreted by a particular cell type play important roles in regulation of many physiological processes via paracrine/autocrine mechanisms and they are of increasing interest as potential biomarkers and therapeutic targets. Knowledge of the proteins released by cells in conditioned media in vitro as well as their biological functions and related pathways will allow a better understanding of pathological conditions and mechanisms in vivo. It is well known that there is a bi-directional crosstalk between adipose tissue and tumour cells. Adipose tissue modulates the tumour microenvironment by promoting angiogenesis, affecting immune cells and altering metabolism to support growth and survival of metastatic cancer cells. On the other hand, tumour cells would induce adipose tissue to secrete several molecules that would stimulate adhesion, migration, and invasion, and would also induce adipocyte cells to dedifferentiate into pre-adipocytes and, then, reprogram them into cancer-associated adipocytes that would stimulate cancer progression.

This study showed that the quantity, number and variety of proteins detected in CMs-T was higher than in CM-BPH; also, multiple unique proteins were detected under disease progress. These findings indicate the molecular diversity that exist in the adipose tissue of cancer patients with respect to adipose tissue of patients with benign disease and showed that a more active heterotypic crosstalk could promote tumourigenicity, as we and others have previously reported $(6,7,10,81)$.

Although PPAT collected for this study is not in direct contact with tumour mass, the absolute absence of tumour cells in PPAT of patients in T3 stage cannot be ruled out. We can speculate that if there were tumour cells, their quantity would be low and probably the sensitivity of MS would not allow for detection of the proteins released by these cells. Moreover, after collecting the CMs, the PPAT tissues were subjected to collagenase treatment, for further culture and growth of stromal vascular fraction up to passage 4 (p4) obtaining an adipose stem cell (ASC) culture, that under microscopic observation did not show epithelial cell morphology (data not shown). Several proteins, which were not previously associated with adipose tissue, were also found in this secretome analysis. Many of them were reported in the secretome of PCa cells, or in co-cultures of tumour cells of different origins with the associated stromal cells. Although the presence of tumour cells in PPAT from patients in T3 stage cannot be ruled out, an "ex vivo heterotypic secretome" could be studied and a protein profile approximate to that present in vivo would be observed in CMs. It is important to consider the possible presence of cell-derived vesicles (exosomes) in CMs. Exosomes were the most represented cellular component in the three CMs. Exosomes transport molecular signals between cells and their protein content profile changes in response to the microenvironment. The 
proteins found in the PPAT secretome of patients with $\mathrm{PCa}$ could derive from the tumour and packaged in exosomes, because some proteins have not been reported in the adipose tissue. Using ex vivo cultures and MS, it was possible to identify several proteins that are intimately involved in the biology of adipose tissue and, also, several potential molecules secreted by PPAT which could be associated with pro-tumourigenic biological processes. Finally, proteins that had not been previously documented in adipose tissue and appeared secreted in PPAT-CMs during the course of the disease were identified. They must be subjected to functional evaluation and there is need for further validation using a larger cohort of patients. Also, many proteins have not been described in the context of adipocyte biology and their exact function needs to be elucidated. Further examination of their expression profiles will provide mechanistic insights into adipose tissue physiology and pathology.

Our study has certain limitations. Proteins found do not derive only from adipose cells, but also from other cell types including inflammatory cells and blood vessels and, thus, cannot be assigned to a specific cell type. Some proteins could also be originated from damaged cells despite the fact that the tissue was carefully treated and, also, proteomic screenings cannot identify all proteins in a solution. The small number of samples used in this study reduces the power of the analysis.

This research represents a further step in the knowledge of the PPAT microenvironment, and provides data on differentially expressed proteins and signalling pathways, and strongly suggests a role for the adipose depots depending on its anatomical location and the disease. A deeper knowledge of these mechanisms will reveal several potential targets for prostate cancer and/or benign disease treatment.

\section{Conflicts of Interest}

The Authors have no potential conflict of interest in the present work.

\section{Acknowledgements}

The Authors wish to thank the patients for their participation in the study and the team of the Urology Department, Hospital de Clínicas "José de San Martín" for collecting adipose tissue. We also are gratefully to Dr. Silvia Moreno and Dr. Pia Valacco from Proteomics Core Facility CEQUIBIEM for support and Dr. Marcela Bolontrade for her helpful comments in proteomic analysis. This study was supported by the Argentine National Cancer Institute 2014-2016, as well a generous donation from Fundación Honorio Bigand.

\section{References}

1 Park J, Euhus DM and Scherer PE: Paracrine and endocrine effects of adipose tissue on cancer development and progression. Endocr Rev 32(4): 550-570, 2011.
2 Kidd S, Spaeth E, Watson K, Burks J, Lu H, Klopp A, Andreeff $\mathrm{M}$ and Marini FC: Origins of the tumor microenvironment: quantitative assessment of adipose-derived and bone marrowderived stroma. PLoS One 7(2): e30563, 2012.

3 Hong H, Koch MO, Foster RS, Bihrle R, Gardner TA, Fyffe J, Ulbright TM, Eble JN and Cheng L: Anatomic distribution of periprostatic adipose tissue: a mapping study of 100 radical prostatectomy specimens. Cancer 97(7): 1639-1643, 2003.

4 Wu Y, Kim JY, Zhou S and Smas CM: Differential screening identifies transcripts with depot-dependent expression in white adipose tissues. BMC Genomics 9: 397, 2008.

5 Mistry T, Digby JE, Desai KM and Randeva HS: Obesity and prostate cancer: a role for adipokines. Eur Urol 52(1): 46-53, 2007.

6 Finley DS, Calvert VS, Inokuchi J, Lau A, Narula N, Petricoin EF, Zaldivar F, Santos R, Tyson DR and Ornstein DK: Periprostatic adipose tissue as a modulator of prostate cancer aggressiveness. J Urol 182(4): 1621-1627, 2009.

7 Fletcher SJ, Sacca PA, Pistone-Creydt M, Colo FA, Serra MF, Santino FE, Sasso CV, Lopez-Fontana CM, Caron RW, Calvo $\mathrm{JC}$ and Pistone-Creydt V: Human breast adipose tissue: characterization of factors that change during tumor progression in human breast cancer. J Exp Clin Cancer Res 36(1): 26, 2017.

8 Karagiannis GS, Pavlou MP and Diamandis EP: Cancer secretomics reveal pathophysiological pathways in cancer molecular oncology. Mol Oncol 4(6): 496-510, 2010.

9 Kim KY, Baek A, Park YS, Park MY, Kim JH, Lim JS, Lee MS, Yoon SR, Lee HG, Yoon Y, Yoon DY and Yang Y: Adipocyte culture medium stimulates invasiveness of MDAMB-231 cell via CCL20 production. Oncol Rep 22(6): 14971504, 2009.

10 Sacca PA, Creydt VP, Choi H, Mazza ON, Fletcher SJ, Vallone VB, Scorticati C, Chasseing NA and Calvo JC: Human periprostatic adipose tissue: its influence on prostate cancer cells. Cell Physiol Biochem 30(1): 113-122, 2012.

11 Schnabele K, Roser S, Rechkemmer G, Hauner H and Skurk T: Effects of adipocyte-secreted factors on cell cycle progression in HT29 cells. Eur J Nutr 48(3): 154-161, 2009.

12 Culig Z: Interleukin-6 as a therapy target in oral squamous carcinoma. Expert Opin Ther Targets 17(1): 53-59, 2013.

13 Strong AL, Burow ME, Gimble JM and Bunnell BA: Concise review: The obesity cancer paradigm: exploration of the interactions and crosstalk with adipose stem cells. Stem Cells 33(2): 318-326, 2015.

14 Laurent V, Guerard A, Mazerolles C, Le Gonidec S, Toulet A, Nieto L, Zaidi F, Majed B, Garandeau D, Socrier Y, Golzio M, Cadoudal T, Chaoui K, Dray C, Monsarrat B, Schiltz O, Wang YY, Couderc B, Valet P, Malavaud B and Muller C: Periprostatic adipocytes act as a driving force for prostate cancer progression in obesity. Nat Commun 7: 10230, 2016.

15 Venkatasubramanian PN, Brendler CB, Plunkett BA, Crawford SE, Fitchev PS, Morgan G, Cornwell ML, McGuire MS, Wyrwicz AM and Doll JA: Periprostatic adipose tissue from obese prostate cancer patients promotes tumor and endothelial cell proliferation: a functional and MR imaging pilot study. Prostate 74(3): 326-335, 2014.

16 Zhang Q, Sun LJ, Yang ZG, Zhang GM and Huo RC: Influence of adipocytokines in periprostatic adipose tissue on prostate cancer aggressiveness. Cytokine 85: 148-156, 2016. 
17 Lapeire L, Hendrix A, Lecoutere E, Van Bockstal M, Vandesompele J, Maynard D, Braems G, Van Den Broecke R, Muller C, Bracke M, Cocquyt V, Denys H and De Wever O: Secretome analysis of breast cancer-associated adipose tissue to identify paracrine regulators of breast cancer growth. Oncotarget 8(29): 47239-47249, 2017.

18 Alvarez-Llamas G, Szalowska E, de Vries MP, Weening D, Landman K, Hoek A, Wolffenbuttel BH, Roelofsen H and Vonk RJ: Characterization of the human visceral adipose tissue secretome. Mol Cell Proteomics 6(4): 589-600, 2007.

19 Stastna M and Van Eyk JE: Secreted proteins as a fundamental source for biomarker discovery. Proteomics 12(4-5): 722-735, 2012.

20 Pathan M, Keerthikumar S, Chisanga D, Alessandro R, Ang CS, Askenase P, Batagov AO, Benito-Martin A, Camussi G, Clayton A, Collino F, Di Vizio D, Falcon-Perez JM, Fonseca P, Fonseka P, Fontana S, Gho YS, Hendrix A, Hoen EN, Iraci N, Kastaniegaard K, Kislinger T, Kowal J, Kurochkin IV, Leonardi T, Liang Y, Llorente A, Lunavat TR, Maji S, Monteleone F, Overbye A, Panaretakis T, Patel T, Peinado H, Pluchino S, Principe S, Ronquist G, Royo F, Sahoo S, Spinelli C, Stensballe A, Thery C, van Herwijnen MJC, Wauben M, Welton JL, Zhao $\mathrm{K}$ and Mathivanan S: A novel community driven software for functional enrichment analysis of extracellular vesicles data. J Extracell Vesicles 6(1): 1321455, 2017.

21 Kaspric N, Picard B, Reichstadt M, Tournayre J and Bonnet M: ProteINSIDE to Easily Investigate Proteomics Data from Ruminants: Application to mine proteome of adipose and muscle tissues in bovine foetuses. PLoS One 10(5): e0128086, 2015.

22 Emanuelsson O, Brunak S, von Heijne $G$ and Nielsen $H$ : Locating proteins in the cell using TargetP, SignalP and related tools. Nat Protoc 2(4): 953-971, 2007.

23 Ishihama Y, Oda Y, Tabata T, Sato T, Nagasu T, Rappsilber J and Mann M: Exponentially modified protein abundance index (emPAI) for estimation of absolute protein amount in proteomics by the number of sequenced peptides per protein. Mol Cell Proteomics 4(9): 1265-1272, 2005.

24 Fain JN, Bahouth SW and Madan AK: Haptoglobin release by human adipose tissue in primary culture. J Lipid Res 45(3): 536542, 2004.

25 Zhong J, Krawczyk SA, Chaerkady R, Huang H, Goel R, Bader JS, Wong GW, Corkey BE and Pandey A: Temporal profiling of the secretome during adipogenesis in humans. J Proteome Res 9(10): 5228-5238, 2010.

26 Chen Q, Jin M, Zhu J, Xiao Q and Zhang L: Functions of heterogeneous nuclear ribonucleoproteins in stem cell potency and differentiation. Biomed Res Int 2013: 623978, 2013.

27 Kim J, Choi YS, Lim S, Yea K, Yoon JH, Jun DJ, Ha SH, Kim JW, Kim JH, Suh PG, Ryu SH and Lee TG: Comparative analysis of the secretory proteome of human adipose stromal vascular fraction cells during adipogenesis. Proteomics 10(3): 394-405, 2010.

28 Perez-Sotelo D, Roca-Rivada A, Larrosa-Garcia M, Castelao C, Baamonde I, Baltar J, Crujeiras AB, Seoane LM, Casanueva FF and Pardo M: Visceral and subcutaneous adipose tissue express and secrete functional alpha2hsglycoprotein (fetuin a) especially in obesity. Endocrine 55(2): 435-446, 2017.

29 Chattopadhyay M, Mukherjee S, Chatterjee SK, Chattopadhyay D, Das S, Majumdar SS, Mukhopadhyay S, Mukherjee S and Bhattarcharya S: Impairment of energy sensors, SIRT1 and AMPK, in lipid induced inflamed adipocyte is regulated by Fetuin A. Cell Signal 42: 67-76, 2017.
30 Mori K, Emoto M and Inaba M: Fetuin-A: a multifunctional protein. Recent Pat Endocr Metab Immune Drug Discov 5(2): 124-146, 2011.

31 Sakwe AM, Koumangoye R, Goodwin SJ and Ochieng J: FetuinA ( $\{$ alpha 2 HS-glycoprotein) is a major serum adhesive protein that mediates growth signaling in breast tumor cells. J Biol Chem 285(53): 41827-41835, 2010.

32 Watson K, Koumangoye R, Thompson P, Sakwe AM, Patel T, Pratap S and Ochieng J: Fetuin-A triggers the secretion of a novel set of exosomes in detached tumor cells that mediate their adhesion and spreading. FEBS Lett 586(19): 3458-3463, 2012.

33 Fernandez-Grijalva AL, Aguilar-Lemarroy A, Jave-Suarez LF, Gutierrez-Ortega A, Godinez-Melgoza PA, Herrera-Rodriguez SE, Mariscal-Ramirez I, Martinez-Velazquez M, Gawinowicz MA, Martinez-Silva MG, Cruz-Ramos JA and HernandezGutierrez R: Alpha 2HS-glycoprotein, a tumor-associated antigen (TAA) detected in Mexican patients with early-stage breast cancer. J Proteomics 112: 301-312, 2015.

34 Mintz PJ, Rietz AC, Cardo-Vila M, Ozawa MG, Dondossola E, Do KA, Kim J, Troncoso P, Logothetis CJ, Sidman RL, Pasqualini R and Arap W: Discovery and horizontal follow-up of an autoantibody signature in human prostate cancer. Proc Natl Acad Sci USA 112(8): 2515-2520, 2015.

35 Krautbauer S, Haberl EM, Eisinger K, Pohl R, Rein-Fischboeck L, Rentero C, Alvarez-Guaita A, Enrich C, Grewal T, Buechler $\mathrm{C}$ and Neumeier M: Annexin A6 regulates adipocyte lipid storage and adiponectin release. Mol Cell Endocrinol 439: 419-430, 2017.

36 Xin W, Rhodes DR, Ingold C, Chinnaiyan AM and Rubin MA: Dysregulation of the annexin family protein family is associated with prostate cancer progression. Am J Pathol 162(1): 255-261, 2003.

37 Greening DW, Ji H, Chen M, Robinson BW, Dick IM, Creaney J and Simpson RJ: Secreted primary human malignant mesothelioma exosome signature reflects oncogenic cargo. Sci Rep 6: 32643, 2016.

38 Hegmans JP, Bard MP, Hemmes A, Luider TM, Kleijmeer MJ, Prins JB, Zitvogel L, Burgers SA, Hoogsteden HC and Lambrecht $\mathrm{BN}$ : Proteomic analysis of exosomes secreted by human mesothelioma cells. Am J Pathol 164(5): 1807-1815, 2004.

39 Qi H, Liu S, Guo C, Wang J, Greenaway FT and Sun MZ: Role of annexin A6 in cancer. Oncol Lett 10(4): 1947-1952, 2015.

40 Stockley J, Villasevil ME, Nixon C, Ahmad I, Leung HY and Rajan P: The RNA-binding protein hnRNPA2 regulates betacatenin protein expression and is overexpressed in prostate cancer. RNA Biol 11(6): 755-765, 2014.

41 Villarroya-Beltri C, Gutierrez-Vazquez C, Sanchez-Cabo F, Perez-Hernandez D, Vazquez J, Martin-Cofreces N, MartinezHerrera DJ, Pascual-Montano A, Mittelbrunn M and SanchezMadrid F: Sumoylated hnRNPA2B1 controls the sorting of miRNAs into exosomes through binding to specific motifs. Nat Commun 4: 2980, 2013.

42 Ngan E, Kiepas A, Brown CM and Siegel PM: Emerging roles for LPP in metastatic cancer progression. J Cell Commun Signal 12: 143-156, 2018.

43 Ngan E, Stoletov K, Smith HW, Common J, Muller WJ, Lewis JD and Siegel PM: LPP is a Src substrate required for invadopodia formation and efficient breast cancer lung metastasis. Nat Commun 8: 15059, 2017. 
44 Keller M, Hopp L, Liu X, Wohland T, Rohde K, Cancello R, Klos M, Bacos K, Kern M, Eichelmann F, Dietrich A, Schon MR, Gartner D, Lohmann T, Dressler M, Stumvoll M, Kovacs $\mathrm{P}$, DiBlasio AM, Ling C, Binder H, Bluher M and Bottcher Y: Genome-wide DNA promoter methylation and transcriptome analysis in human adipose tissue unravels novel candidate genes for obesity. Mol Metab 6(1): 86-100, 2017.

45 Malik G, Ward MD, Gupta SK, Trosset MW, Grizzle WE, Adam BL, Diaz JI and Semmes OJ: Serum levels of an isoform of apolipoprotein A-II as a potential marker for prostate cancer. Clin Cancer Res 11(3): 1073-1085, 2005.

46 Jayapalan JJ, Ng KL, Razack AH and Hashim OH: Identification of potential complementary serum biomarkers to differentiate prostate cancer from benign prostatic hyperplasia using gel- and lectin-based proteomics analyses. Electrophoresis 33(12): 1855-1862, 2012.

47 Hinrichsen I, Ernst BP, Nuber F, Passmann S, Schafer D, Steinke V, Friedrichs N, Plotz G, Zeuzem S and Brieger A: Reduced migration of MLH1 deficient colon cancer cells depends on SPTAN1. Mol Cancer 13: 11, 2014.

48 Kovak MR, Saraswati S, Goddard SD and Diekman AB: Proteomic identification of galectin-3 binding ligands and characterization of galectin-3 proteolytic cleavage in human prostasomes. Andrology 1(5): 682-691, 2013.

49 Chkourko Gusky H, Diedrich J, MacDougald OA and Podgorski I: Omentum and bone marrow: how adipocyte-rich organs create tumour microenvironments conducive for metastatic progression. Obes Rev 17(11): 1015-1029, 2016.

50 Nieman KM, Kenny HA, Penicka CV, Ladanyi A, Buell-Gutbrod R, Zillhardt MR, Romero IL, Carey MS, Mills GB, Hotamisligil GS, Yamada SD, Peter ME, Gwin K and Lengyel E: Adipocytes promote ovarian cancer metastasis and provide energy for rapid tumor growth. Nat Med 17(11): 1498-1503, 2011.

51 Guaita-Esteruelas S, Guma J, Masana L and Borras J: The peritumoural adipose tissue microenvironment and cancer. The roles of fatty acid binding protein 4 and fatty acid binding protein 5. Mol Cell Endocrinol 462: 107-118, 2018.

52 Ibarretxe D, Girona J, Amigo N, Plana N, Ferre R, Guaita S, Mallol R, Heras M and Masana L: Impact of epidermal fatty acid binding protein on 2D-NMR-assessed atherogenic dyslipidemia and related disorders. J Clin Lipidol 10(2): 330-338 e332, 2016.

53 Herroon MK, Rajagurubandara E, Hardaway AL, Powell K, Turchick A, Feldmann D and Podgorski I: Bone marrow adipocytes promote tumor growth in bone via FABP4-dependent mechanisms. Oncotarget 4(11): 2108-2123, 2013.

54 Ertunc ME, Sikkeland J, Fenaroli F, Griffiths G, Daniels MP, Cao H, Saatcioglu F and Hotamisligil GS: Secretion of fatty acid binding protein aP2 from adipocytes through a nonclassical pathway in response to adipocyte lipase activity. J Lipid Res 56(2): 423-434, 2015.

55 Lazaro I, Ferre R, Plana N, Aragones G, Girona J, Merino J, Heras M, Cabre A and Masana L: Lifestyle changes lower FABP4 plasma concentration in patients with cardiovascular risk. Rev Esp Cardiol (Engl Ed) 65(2): 152-157, 2012.

56 Storch J and Corsico B: The emerging functions and mechanisms of mammalian fatty acid-binding proteins. Annu Rev Nutr 28: 7395, 2008.

57 Adamson J, Morgan EA, Beesley C, Mei Y, Foster CS, Fujii H, Rudland PS, Smith PH and Ke Y: High-level expression of cutaneous fatty acid-binding protein in prostatic carcinomas and its effect on tumorigenicity. Oncogene 22(18): 2739-2749, 2003.
58 Morgan EA, Forootan SS, Adamson J, Foster CS, Fujii H, Igarashi M, Beesley $\mathrm{C}$, Smith $\mathrm{PH}$ and $\mathrm{Ke} \mathrm{Y}$ : Expression of cutaneous fatty acid-binding protein (C-FABP) in prostate cancer: potential prognostic marker and target for tumourigenicitysuppression. Int J Oncol 32(4): 767-775, 2008.

59 Mo F, Lin D, Takhar M, Ramnarine VR, Dong X, Bell RH, Volik SV, Wang K, Xue H, Wang Y, Haegert A, Anderson S, Brahmbhatt S, Erho N, Wang X, Gout PW, Morris J, Karnes RJ, Den RB, Klein EA, Schaeffer EM, Ross A, Ren S, Sahinalp SC, Li Y, Xu X, Wang J, Wang J, Gleave ME, Davicioni E, Sun Y, Wang Y and Collins CC: Stromal gene expression is predictive for metastatic primary prostate cancer. Eur Urol 73: 524-532, 2018.

60 Dahlman I, Elsen M, Tennagels N, Korn M, Brockmann B, Sell $\mathrm{H}$, Eckel $\mathrm{J}$ and Arner P: Functional annotation of the human fat cell secretome. Arch Physiol Biochem 118(3): 84-91, 2012.

61 van Greevenbroek MM: The expanding role of complement in adipose tissue metabolism and lipoprotein function. Curr Opin Lipidol 20(4): 353-354, 2009.

62 Mutch DM, Rouault C, Keophiphath M, Lacasa D and Clement $\mathrm{K}$ : Using gene expression to predict the secretome of differentiating human preadipocytes. Int J Obes (Lond) 33(3): 354-363, 2009.

63 Rutkowski MJ, Sughrue ME, Kane AJ, Mills SA and Parsa AT: Cancer and the complement cascade. Mol Cancer Res 8(11): 1453-1465, 2010.

64 Zhang T, Tseng C, Zhang Y, Sirin O, Corn PG, Li-Ning-Tapia EM, Troncoso P, Davis J, Pettaway C, Ward J, Frazier ML, Logothetis C and Kolonin MG: CXCL1 mediates obesityassociated adipose stromal cell trafficking and function in the tumour microenvironment. Nat Commun 7: 11674, 2016.

65 Zhong L, Roybal J, Chaerkady R, Zhang W, Choi K, Alvarez CA, Tran H, Creighton CJ, Yan S, Strieter RM, Pandey A and Kurie JM: Identification of secreted proteins that mediate cell-cell interactions in an in vitro model of the lung cancer microenvironment. Cancer Res 68(17): 7237-7245, 2008.

66 Zhang X, Yuan X, Shi H, Wu L, Qian H and Xu W: Exosomes in cancer: small particle, big player. J Hematol Oncol 8: 83, 2015.

67 Yi H, Zheng X, Song J, Shen R, Su Y and Lin D: Exosomes mediated pentose phosphate pathway in ovarian cancer metastasis: a proteomics analysis. Int J Clin Exp Pathol 8(12): 15719-15728, 2015.

68 Jung T, Castellana D, Klingbeil P, Cuesta Hernandez I, Vitacolonna M, Orlicky DJ, Roffler SR, Brodt P and Zoller M: CD44v6 dependence of premetastatic niche preparation by exosomes. Neoplasia 11(10): 1093-1105, 2009.

69 Kim SJ, Lee KH, Lee YS, Mun EG, Kwon DY and Cha YS: Transcriptome analysis and promoter sequence studies on early adipogenesis in 3T3-L1 cells. Nutr Res Pract 1(1): 19-28, 2007.

70 Sakamoto S, McCann RO, Dhir R and Kyprianou N: Talin1 promotes tumor invasion and metastasis via focal adhesion signaling and anoikis resistance. Cancer Res 70(5): 1885-1895, 2010.

71 Cavallaro U and Christofori G: Cell adhesion and signalling by cadherins and Ig-CAMs in cancer. Nat Rev Cancer 4(2): 118-132, 2004.

72 He Z, Zhu HH, Bauler TJ, Wang J, Ciaraldi T, Alderson N, Li S, Raquil MA, Ji K, Wang S, Shao J, Henry RR, King PD and Feng GS: Nonreceptor tyrosine phosphatase Shp2 promotes adipogenesis through inhibition of p38 MAP kinase. Proc Natl Acad Sci USA 110(1): E79-88, 2013. 
73 Merfeld-Clauss S, Gollahalli N, March KL and Traktuev DO: Adipose tissue progenitor cells directly interact with endothelial cells to induce vascular network formation. Tissue Eng Part A 16(9): 2953-2966, 2010

74 Liu Q, Harvey CT, Geng H, Xue C, Chen V, Beer TM and Qian DZ: Malate dehydrogenase 2 confers docetaxel resistance via regulations of JNK signaling and oxidative metabolism. Prostate 73(10): 1028-1037, 2013.

75 Chen CY, Abell AM, Moon YS and Kim KH: An advanced glycation end product (AGE)-receptor for AGEs (RAGE) axis restores adipogenic potential of senescent preadipocytes through modulation of p53 protein function. J Biol Chem 287(53): 4449844507, 2012.

76 Tan B, Shen L, Yang K, Huang D, Li X, Li Y, Zhao L, Chen J, Yi Q, Xu H, Tian J and Zhu J: C6 glioma-conditioned medium induces malignant transformation of mesenchymal stem cells: Possible role of S100B/RAGE pathway. Biochem Biophys Res Commun 495(1): 78-85, 2018.

77 John A, Gorzelanny C, Bauer AT, Schneider SW and Bolenz C: Role of the coagulation system in genitourinary cancers: Review. Clin Genitourin Cancer, 2017. doi: 10.1016/j.clgc.2017.07.013. [Epub ahead of print]

78 Falanga A, Marchetti M and Vignoli A: Coagulation and cancer: biological and clinical aspects. J Thromb Haemost 11(2): 223233, 2013.

79 Alevizopoulos A, Tyritzis S, Leotsakos I, Anastasopoulou I, Pournaras C, Kotsis P, Katsarou O, Alamanis C, Stravodimos K and Constantinides $\mathrm{C}$ : Role of coagulation factors in urological malignancy: A prospective, controlled study on prostate, renal and bladder cancer. Int J Urol 24(2): 130-136, 2017.

80 Allott EH, Lysaght J, Cathcart MC, Donohoe CL, Cummins R, McGarrigle SA, Kay E, Reynolds JV and Pidgeon GP: MMP9 expression in oesophageal adenocarcinoma is upregulated with visceral obesity and is associated with poor tumour differentiation. Mol Carcinog 52(2): 144-154, 2013.

81 Ribeiro R, Monteiro C, Cunha V, Oliveira MJ, Freitas M, Fraga A, Principe P, Lobato C, Lobo F, Morais A, Silva V, SanchesMagalhaes J, Oliveira J, Pina F, Mota-Pinto A, Lopes C and Medeiros R: Human periprostatic adipose tissue promotes prostate cancer aggressiveness in vitro. J Exp Clin Cancer Res 31: 32, 2012.

82 Lehr S, Hartwig S, Lamers D, Famulla S, Muller S, Hanisch FG, Cuvelier C, Ruige J, Eckardt K, Ouwens DM, Sell H and Eckel $\mathrm{J}$ : Identification and validation of novel adipokines released from primary human adipocytes. Mol Cell Proteomics 11(1): M111 010504, 2012.

83 DeLany JP, Floyd ZE, Zvonic S, Smith A, Gravois A, Reiners E, Wu X, Kilroy G, Lefevre M and Gimble JM: Proteomic analysis of primary cultures of human adipose-derived stem cells: modulation by Adipogenesis. Mol Cell Proteomics 4(6): 731-740, 2005.

84 Zvonic S, Lefevre M, Kilroy G, Floyd ZE, DeLany JP, Kheterpal I, Gravois A, Dow R, White A, Wu X and Gimble JM: Secretome of primary cultures of human adipose-derived stem cells: modulation of serpins by adipogenesis. Mol Cell Proteomics 6(1): 18-28, 2007.

85 Law RH, Zhang Q, McGowan S, Buckle AM, Silverman GA, Wong W, Rosado CJ, Langendorf CG, Pike RN, Bird PI and Whisstock JC: An overview of the serpin superfamily. Genome Biol 7(5): 216, 2006

86 Chao J, Li P and Chao L: Kallistatin suppresses cancer development by multi-factorial actions. Crit Rev Oncol Hematol 113: 71-78, 2017
87 Bhutia YD, Babu E, Ramachandran S, Yang S, Thangaraju M and Ganapathy V: SLC transporters as a novel class of tumour suppressors: identity, function and molecular mechanisms. Biochem J 473(9): 1113-1124, 2016.

88 Zhang Y, O'Keefe RJ and Jonason JH: BMP-TAK1 (MAP3K7) induces adipocyte differentiation through PPARgamma signaling. J Cell Biochem 118(1): 204-210, 2017.

89 Chen Y, Wang X, Duan C, Chen J, Su M, Jin Y, Deng Y, Wang D, Chen C, Zhou L, Cheng J, Wang W and Xi Q: Loss of TAB3 expression by shRNA exhibits suppressive bioactivity and increased chemical sensitivity of ovarian cancer cell lines via the NF-kappaB pathway. Cell Prolif 49(6): 657-668, 2016.

90 Rehman I, Evans CA, Glen A, Cross SS, Eaton CL, Down J, Pesce G, Phillips JT, Yen OS, Thalmann GN, Wright PC and Hamdy FC: iTRAQ identification of candidate serum biomarkers associated with metastatic progression of human prostate cancer. PLoS One 7(2): e30885, 2012.

91 Jia X, Chen J, Sun S, Yang W, Yang S, Shah P, Hoti N, Veltri B and Zhang $\mathrm{H}$ : Detection of aggressive prostate cancer associated glycoproteins in urine using glycoproteomics and mass spectrometry. Proteomics 16(23): 2989-2996, 2016.

92 Murri M, Insenser M, Bernal-Lopez MR, Perez-Martinez P, Escobar-Morreale HF and Tinahones FJ: Proteomic analysis of visceral adipose tissue in pre-obese patients with type 2 diabetes. Mol Cell Endocrinol 376(1-2): 99-106, 2013.

93 Oberbach A, Bluher M, Wirth H, Till H, Kovacs P, Kullnick Y, Schlichting N, Tomm JM, Rolle-Kampczyk U, Murugaiyan J, Binder H, Dietrich A and von Bergen M: Combined proteomic and metabolomic profiling of serum reveals association of the complement system with obesity and identifies novel markers of body fat mass changes. J Proteome Res 10(10): 4769-4788, 2011.

94 Cao Y, Lundwall A, Gadaleanu V, Lilja H and Bjartell A: Antithrombin is expressed in the benign prostatic epithelium and in prostate cancer and is capable of forming complexes with prostate-specific antigen and human glandular kallikrein 2. Am J Pathol 161(6): 2053-2063, 2002.

95 Chen WZ, Pang B, Yang B, Zhou JG and Sun YH: Differential proteome analysis of conditioned medium of BPH-1 and LNCaP cells. Chin Med J (Engl) 124(22): 3806-3809, 2011.

96 Kamal AH, Kim WK, Cho K, Park A, Min JK, Han BS, Park SG, Lee $\mathrm{SC}$ and Bae KH: Investigation of adipocyte proteome during the differentiation of brown preadipocytes. J Proteomics 94: 327336, 2013.

97 Kawaguchi N, Sundberg C, Kveiborg M, Moghadaszadeh B, Asmar M, Dietrich N, Thodeti CK, Nielsen FC, Moller P, Mercurio AM, Albrechtsen R and Wewer UM: ADAM12 induces actin cytoskeleton and extracellular matrix reorganization during early adipocyte differentiation by regulating beta1 integrin function. J Cell Sci 116(Pt 19): 3893-3904, 2003.

98 Ai J, Jin T, Yang L, Wei Q, Yang Y, Li H and Zhu Y: Vinculin and filamin-C are two potential prognostic biomarkers and therapeutic targets for prostate cancer cell migration. Oncotarget 8(47): 82430-82436, 2017. 